\title{
SUSTAINABLE DEVELOPMENT OF ECO-TOURISM IN NORTH SINAI (AN APPLIED ST479UDY ON AL-ARISH CITY)
}

\author{
Heba Fathi Shourrab ${ }^{1}$,Mohammed Hassan Atwa, Mervat Abd El-Aziz Nasr ${ }^{2}$ \\ ${ }^{1}$ Department of architecture ,El-Arish High Institute for Engineering \&Technology, El-Arish, \\ North Sinai, Egypt. \\ ${ }^{2}$ Department Of Architecture and urban planning, Faculty Of Engineering Of Suez Canal \\ University ,Ismailia ,Egypt \\ *Corresponding author Email : $\underline{\text { Heba.Doody@Gmail.Com }}$
}

\begin{abstract}
Sustainable Eco-tourism development is one of the recent trends that emerged as a result of the negative changes that the environment witnessed in the recent period.

This has led to the interest of many tourism countries in sustainable Eco-tourism development plans, Hence the research problem, which is the lack of clear sustainable development standards and mechanisms to adequately utilize the available resources in North Sinai, whether natural or human. Therefore, the objectives of the research were to study the potential of natural and human resources and how to apply the criteria for sustainable tourism development, The research paper follows the analytical approach that relies on analyzing data on the tourism sector and the human and natural potentials in North Sinai Governorate, And also the applied approach that relies on conducting a study on ecotourism areas in North Sinai.
\end{abstract}

KEYWORDS: Ecotourism- Sustainable Development - Tourism in Arish - North Sinai Governorate.

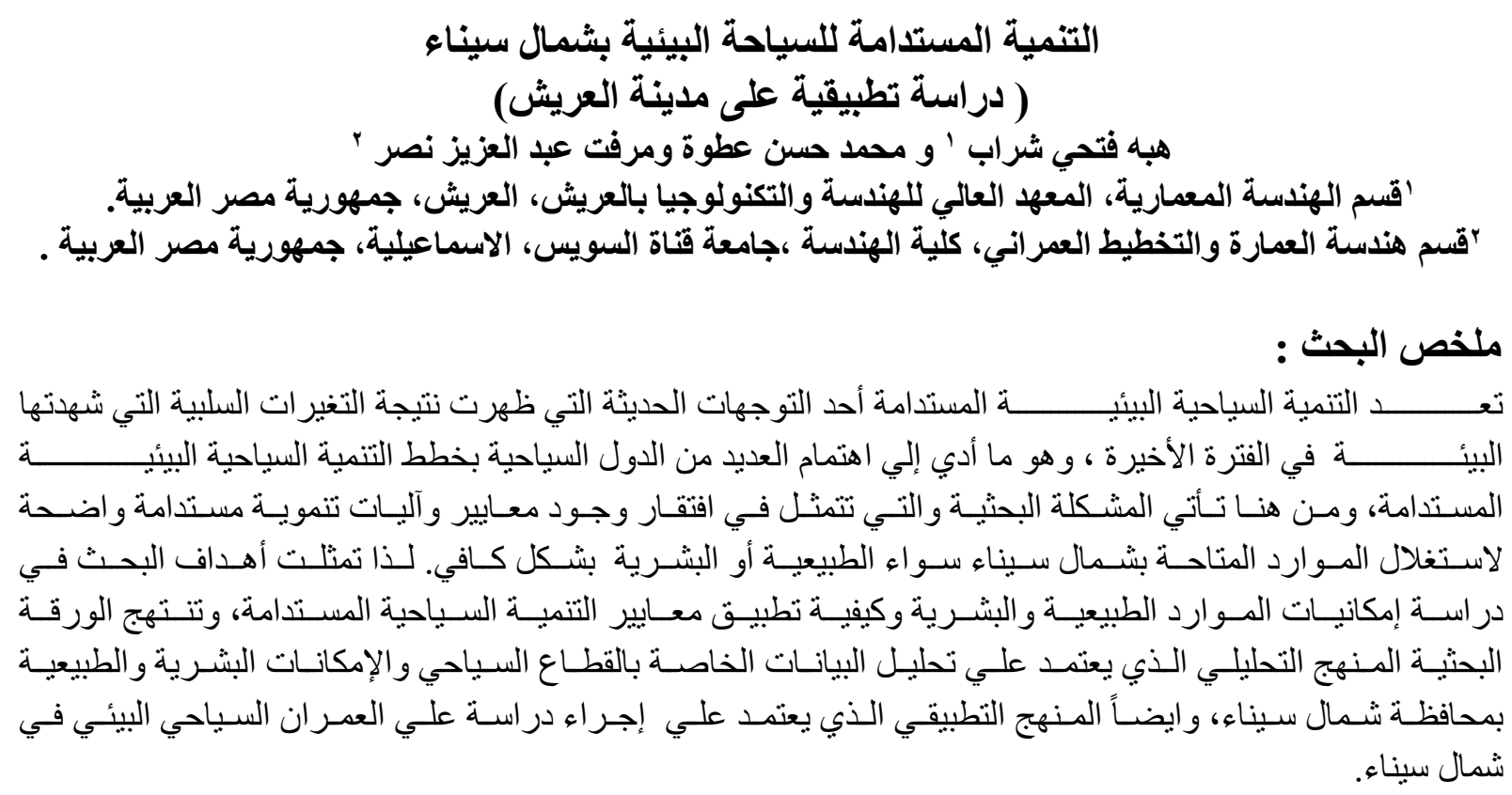




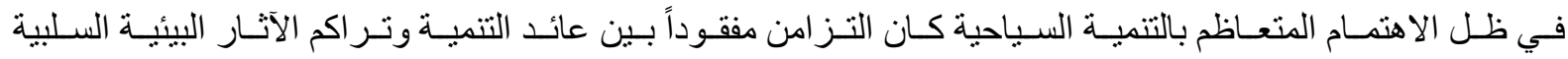

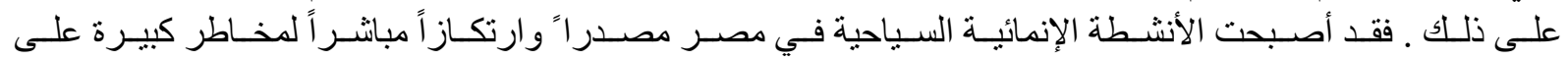

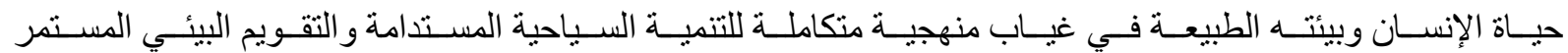
للمناطق السياحية .

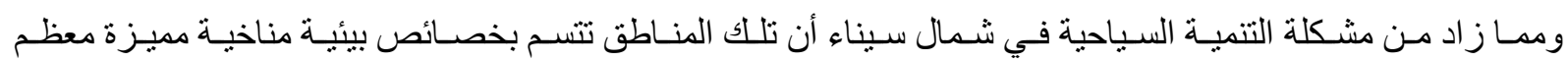

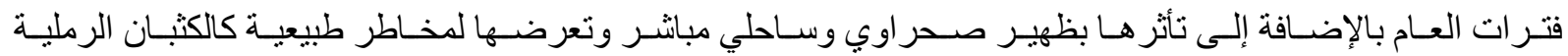

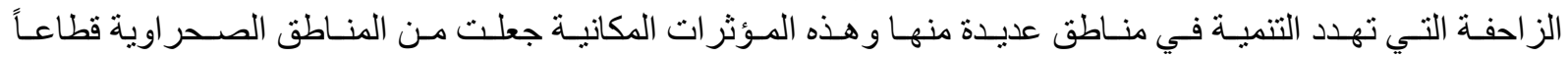

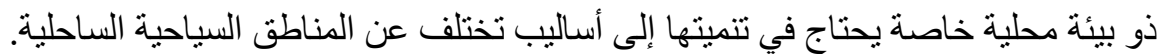

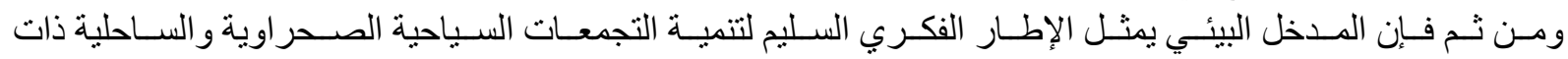

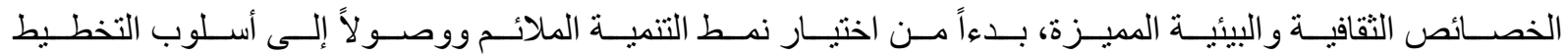
و التصميم للتجمعات السياحية.

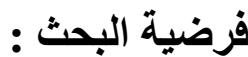

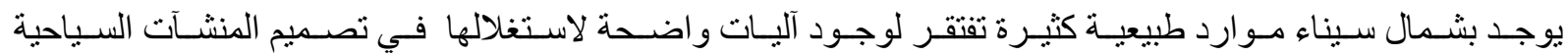

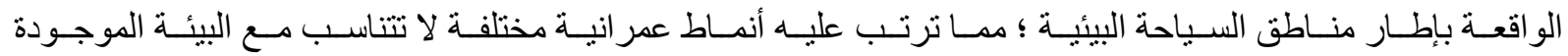

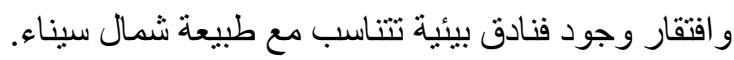

أهداف البحث

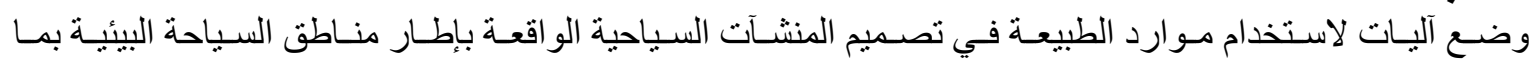
يتلاءم مع بيئة شمال سيناء.

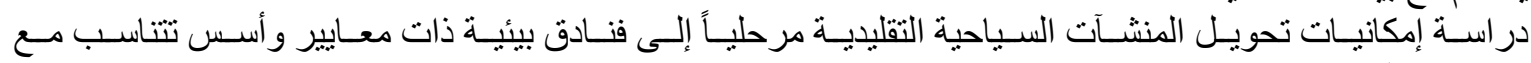
طبيعة شمال سيناء. منهجية البحث طنمال

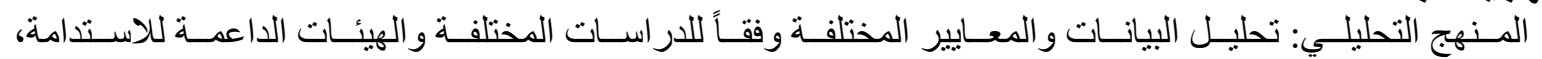
تحليل التجارب وفقاً للمعايير التي تم استخلاصها.

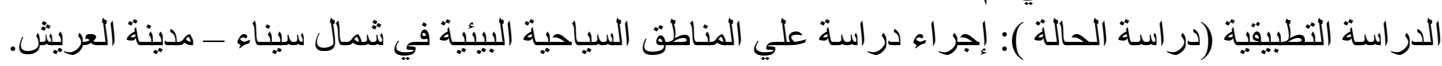
محتوي البحث.

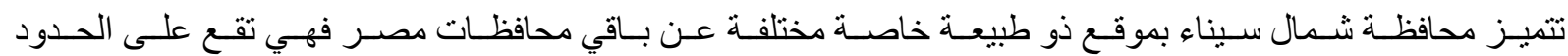

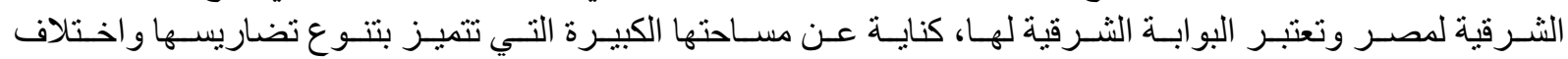

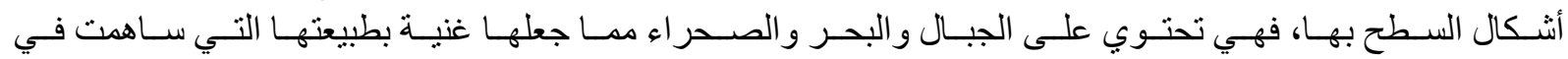
تشكيل شخصية المحافظة عن غير ها من باقي محافظات الجمهي الجهورية.

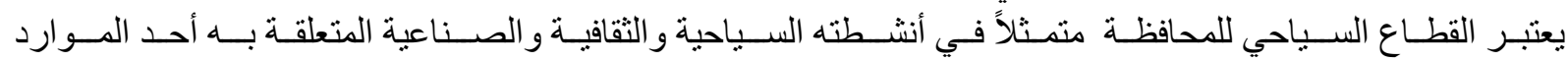

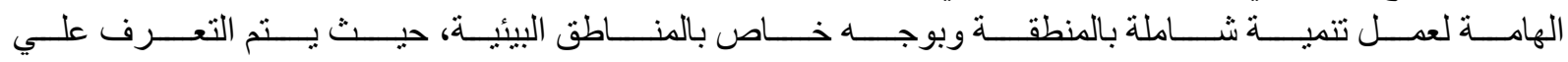

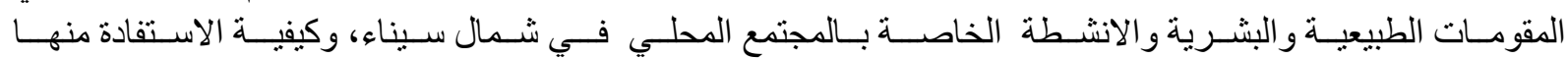

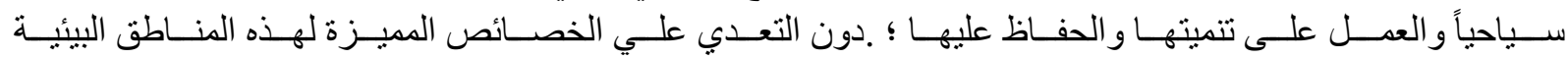

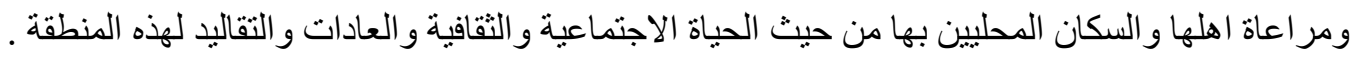

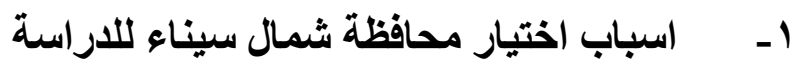

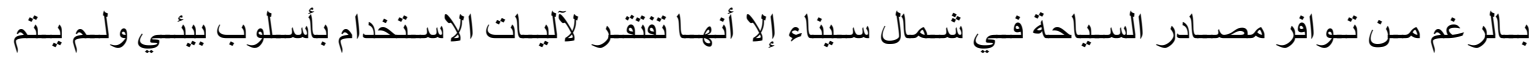

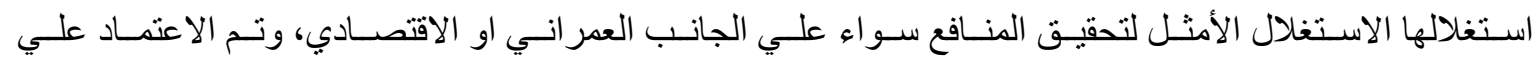

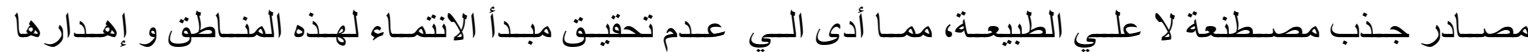


وجـود منــاطق ذات طبيعـة بيئيــة خاصــة مهـددة بالتـدهور وتـدمير بعـض الأنظمـة البيئيـة بهـا نتيجـة أسـاليب التنمية غير المدروسة، مع البناء العشو ائي للمنشآت السياحية بها.

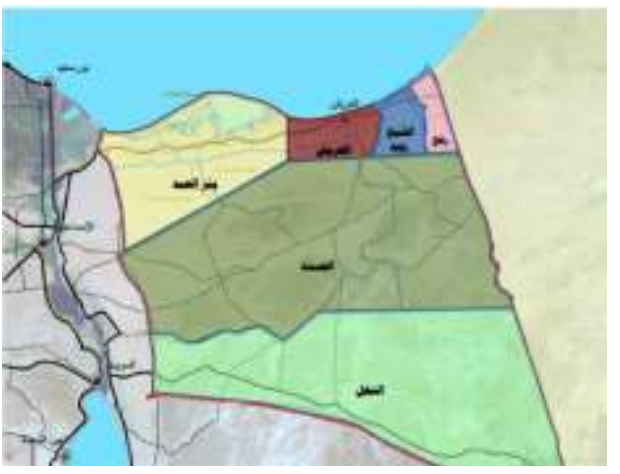

شكل (1) :موقع محافظة شمال سيناء من جمهورية مصر العربية

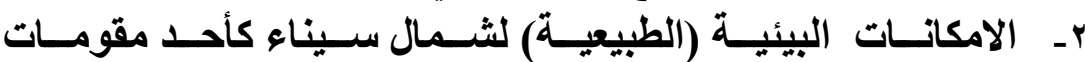
السياحة البيئية

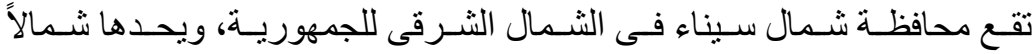

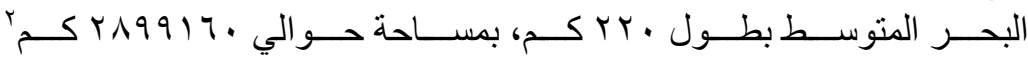

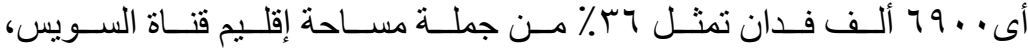
9 \% \% تقريباً من جملة مساحة الجمهورية.

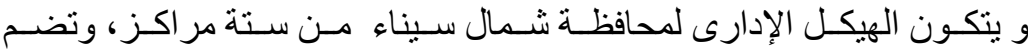

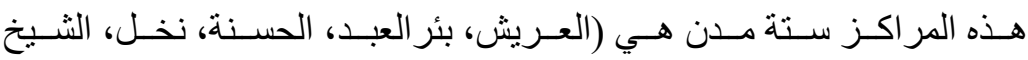

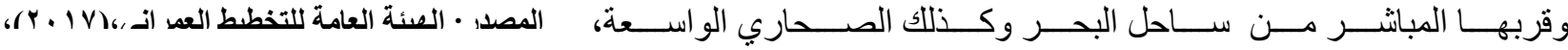

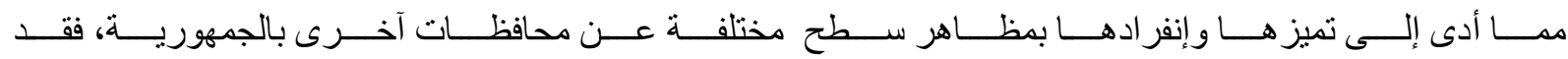
إنقسمت الملامح الجغر افية فى شمال سيناء إلى نوعين متميزين هم, شكل (؟):

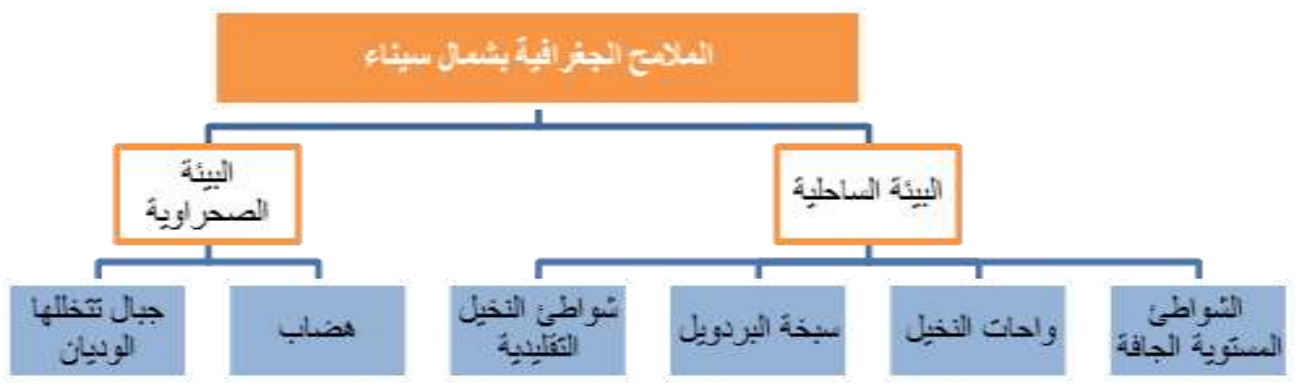

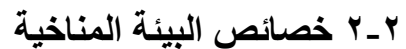

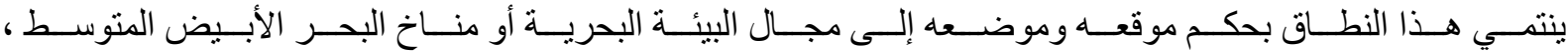

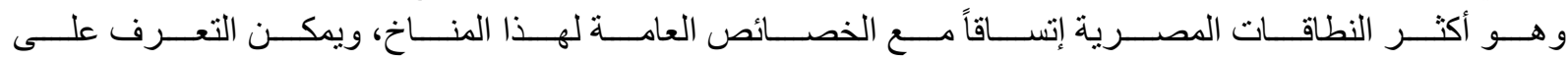

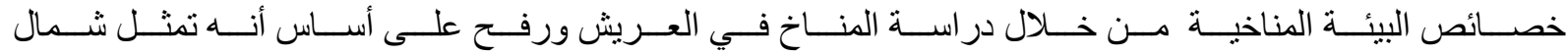

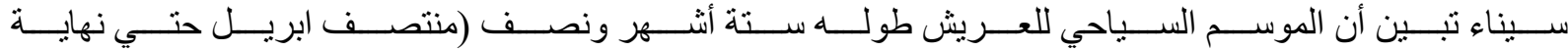
(كتوبر ).

\section{r- - المقومات البشرية كأحد مقومات السياحة البيئية بشمال سيناء}

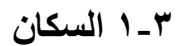

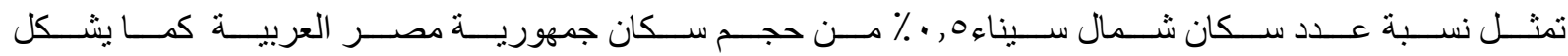

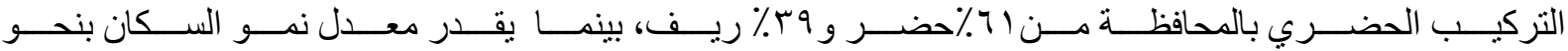

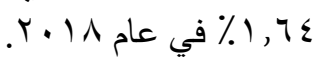

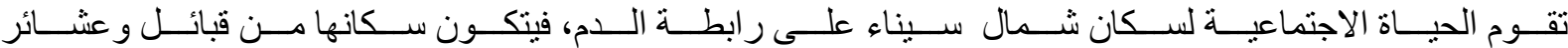

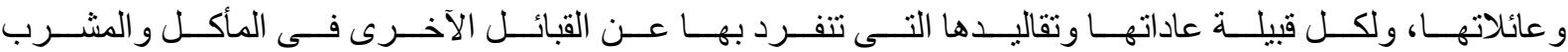
و والمسكن و الملبس. 


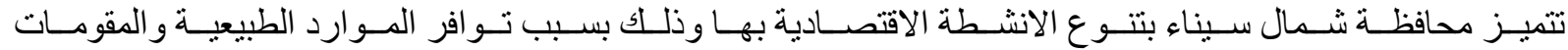

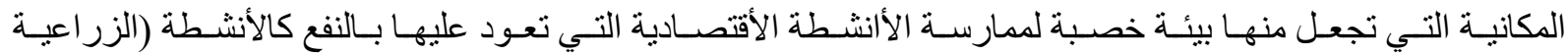

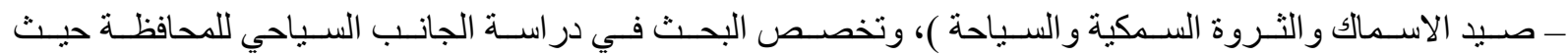
يعرض اهم المقومات السياحية بها كما يلي:

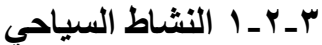

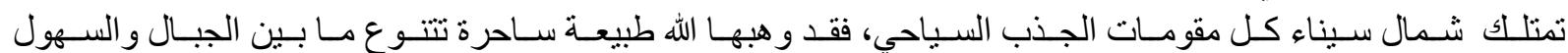

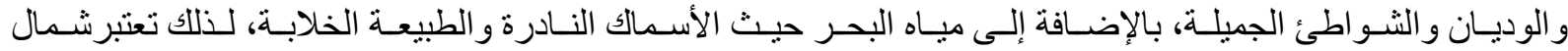

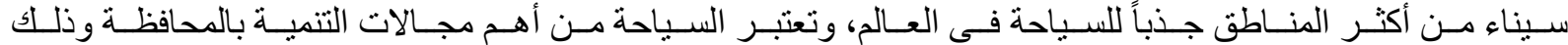

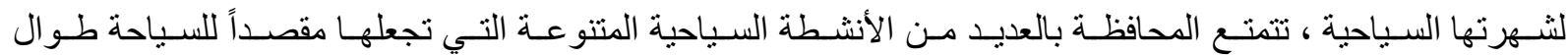
العام، وفي جذول ( () حصر لأهم الأنشطة السياحية بشمال سيناء و أماكن تو اجدها (مقوماتها):

جدول (1) : يوضح الأنثطة السياحية بمحافظة شمال سيناء

\begin{tabular}{|c|c|}
\hline المقومات & ع \\
\hline 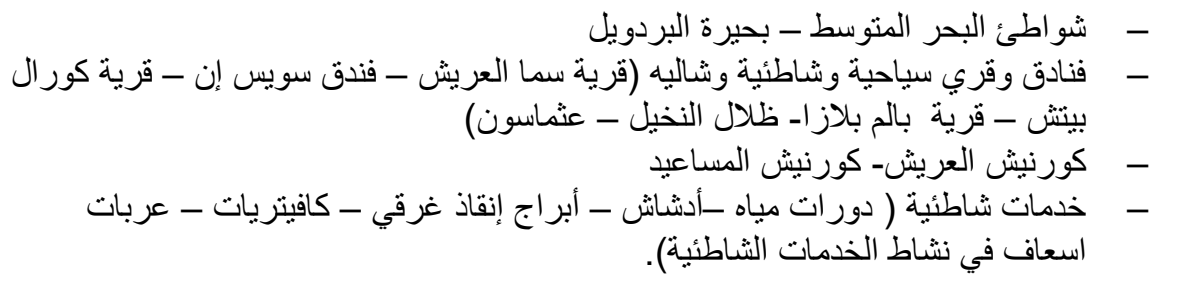 & السياحة الترفيهية (الثاطئية \\
\hline 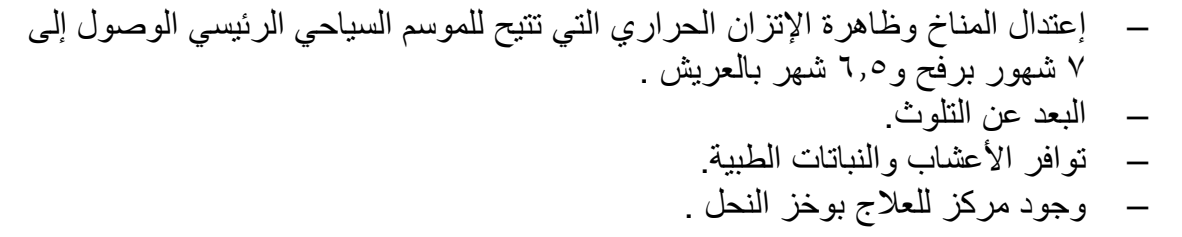 & السياحة العلاجية \\
\hline - & سياحة المحميات الطبيعية \\
\hline 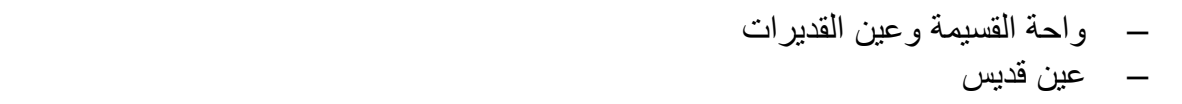 & سياحة الو احات و العيون \\
\hline 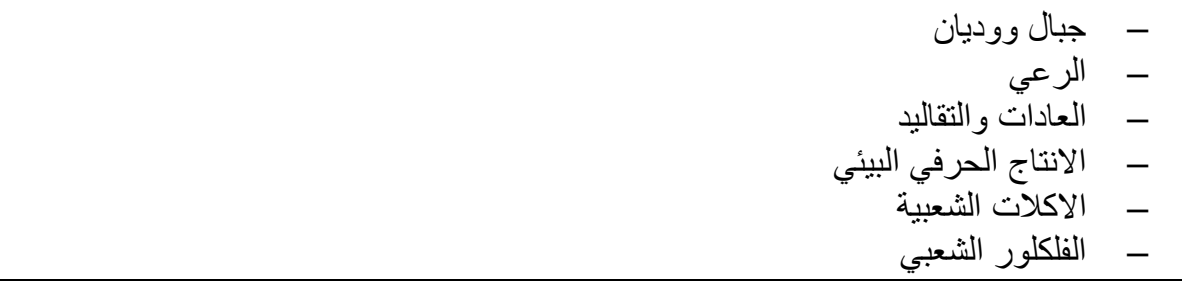 & سياحة الصحر اء \\
\hline 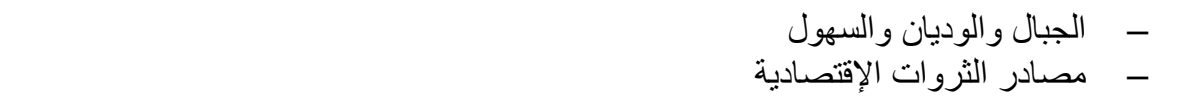 & السياحة العلمية و الجيولوجية \\
\hline 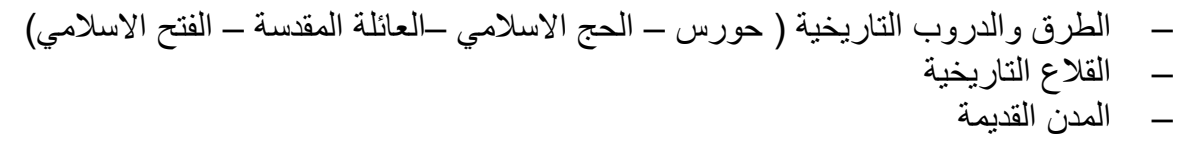 & السياحة الثقافية و التاريخية \\
\hline
\end{tabular}




$$
\begin{aligned}
& \text { - - ميناء رفح البري }
\end{aligned}
$$

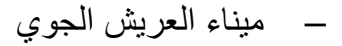

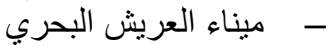

$$
\begin{aligned}
& \text { - ميناء العوجة البري البري } \\
& \text { - - طريق الوسط (الإسماعيلية - نخل - نوييع ) }
\end{aligned}
$$

\section{ع ـ أنماط العمران البيئي في المجتمعات المحلية بشمال سيناء}

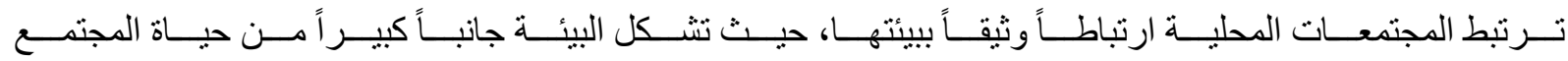

و أنشطته الاقتصادية (فالبيئة الصحر اوية على سبيل المثال قد تدفع السكان إلى العمل بالرعي) .

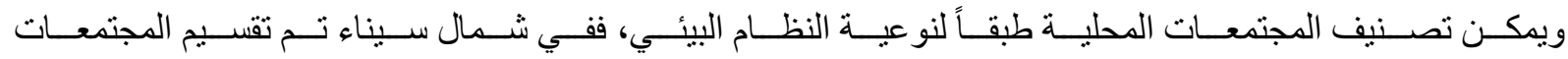
المحلية إلى قسمين رئيسيين تبعاً لنو عية النظام البيئي و هي : لإني ـ ــ المجتمعات الصحراوية البدوية

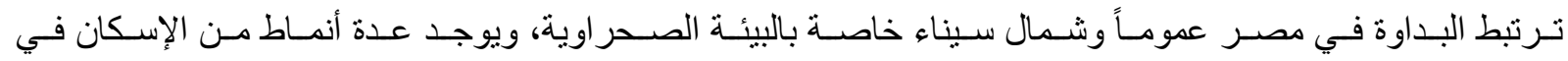

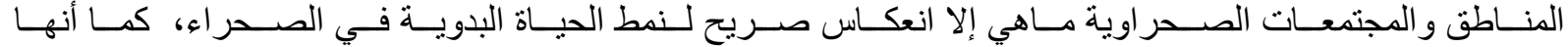

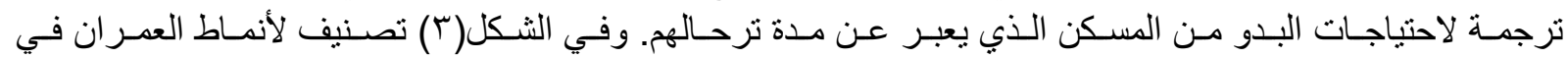

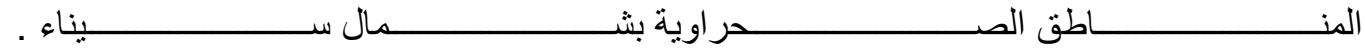

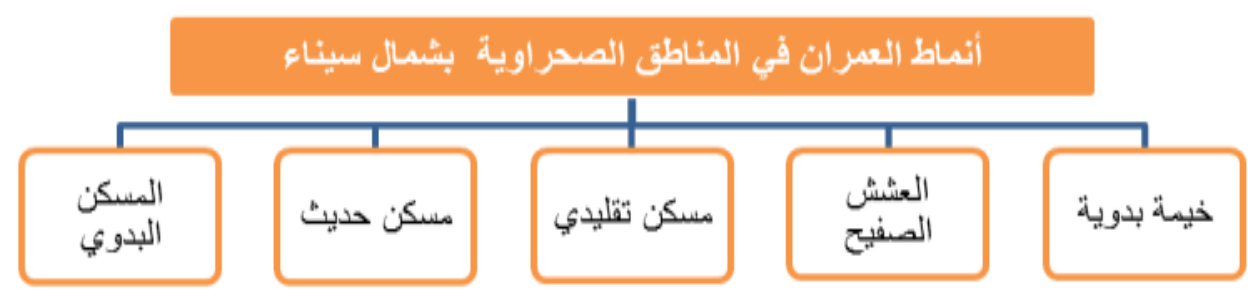

شكل (َّ): انماط العمران في المناطق الصحراوية بشمال سيناء

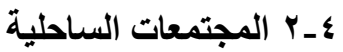

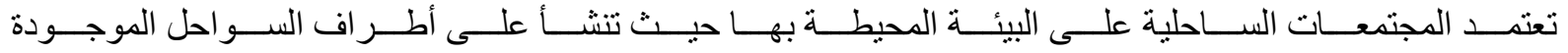

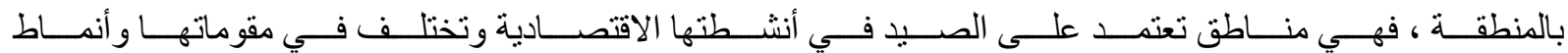

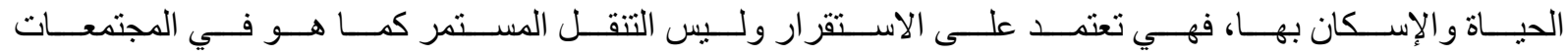
البدوية. وفي شكل (ع) ) توضيح لأهم انماط الاسكان بالمناطق الساحلية بشمال سيناء.

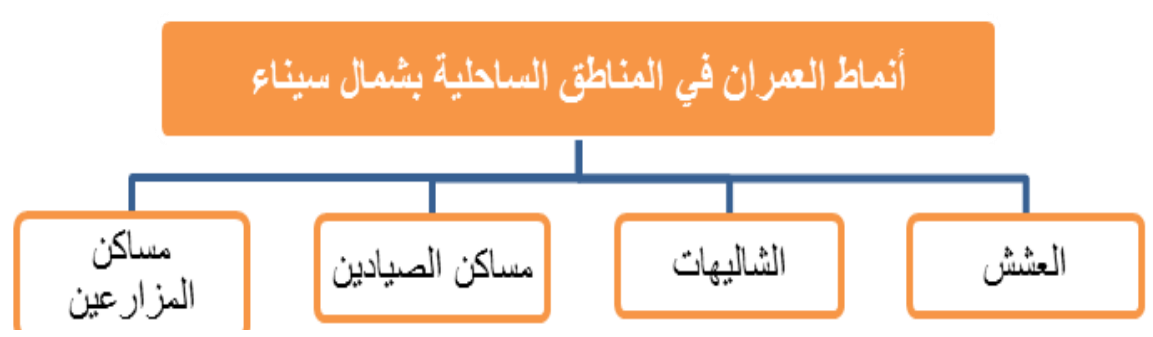

شكل (ء) ): انماط العمران في المناطق الساحلية بشمال سيناء 
مقارنة توضيحية بين المجتمعات الساحلية والمجتمعات الصحراوية بشمال سيناء: جدول (ץ): يوضح الفرق بين المجتمعات الساحلية المجتمعات البدوية الصحر اوية بشمال سيناء

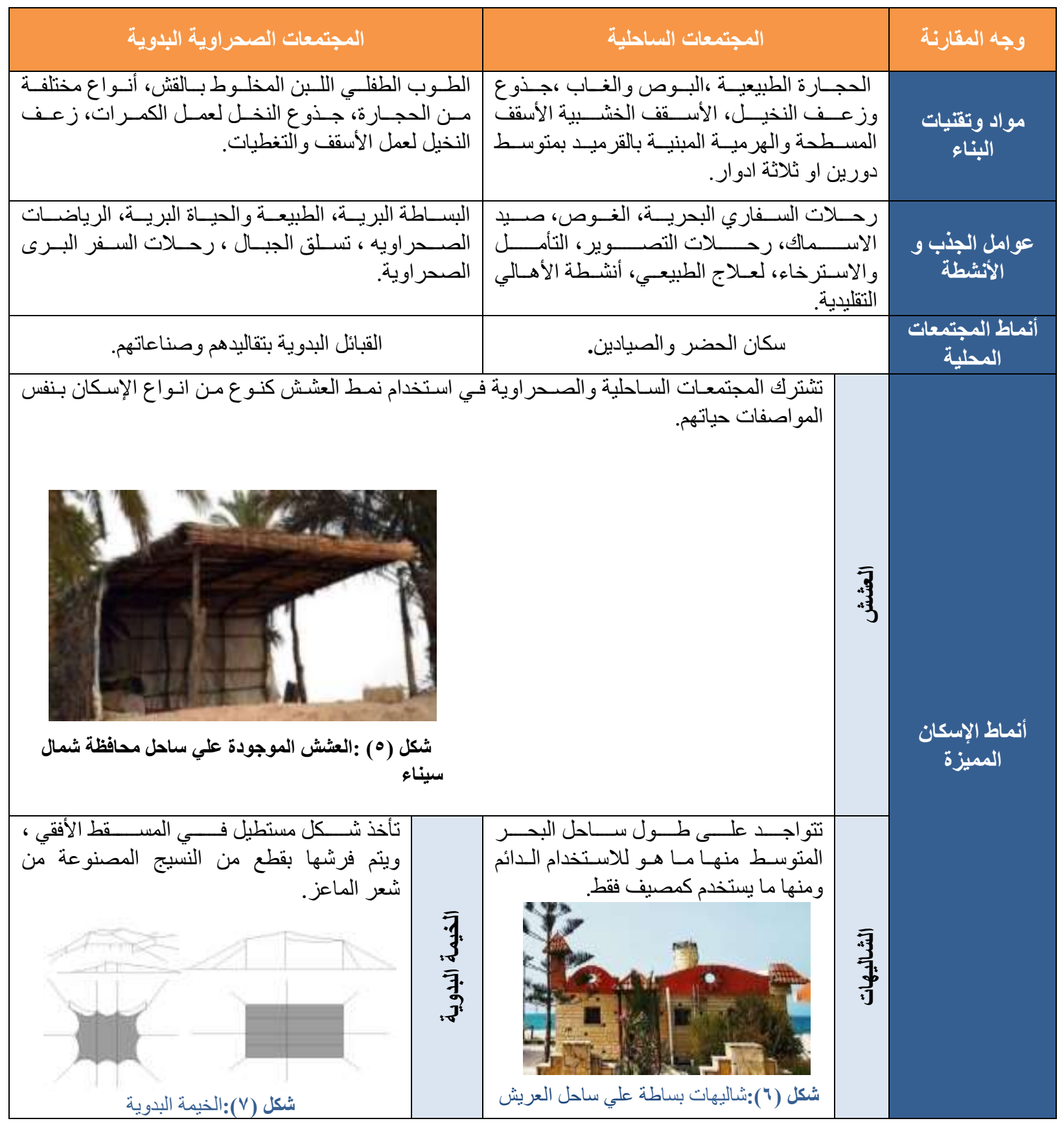




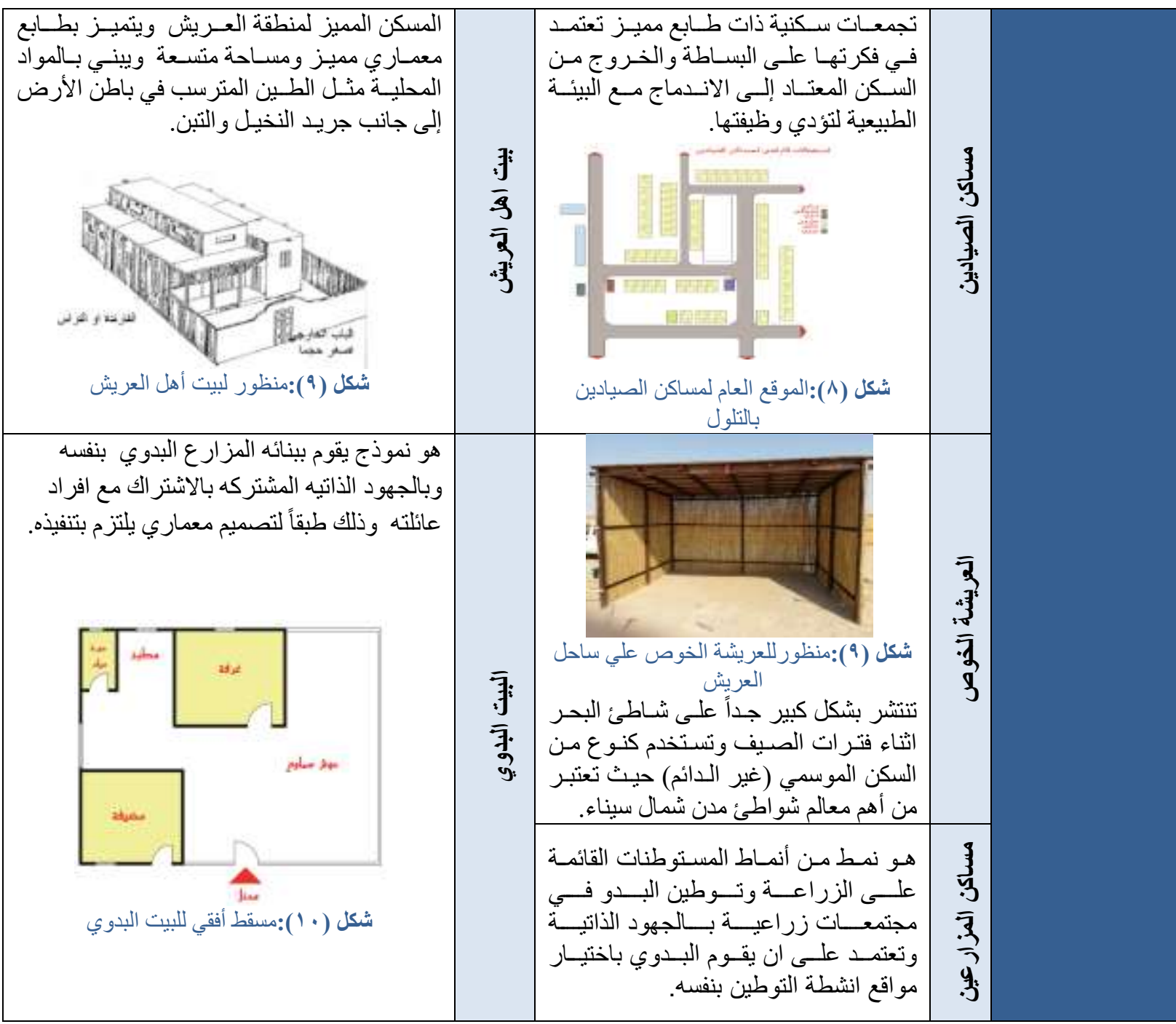

ه تحليل S.W.O.T Analysis للمقومات السياحية البيئية بشمال سيناء

في هذا الجزء قدمت الدراسة تحليل لمقومات السياحة البيئية الموجودة بالمحافظة كما بالجدول (؟) :

جدول (ّ): تحليل s.w.o.t analysis للمقومات السياحية البيئية بثمال سيناء

\begin{tabular}{|c|c|c|c|}
\hline ألتيات & (1) & نقاط الضنف: & نُقاط الثقوة \\
\hline 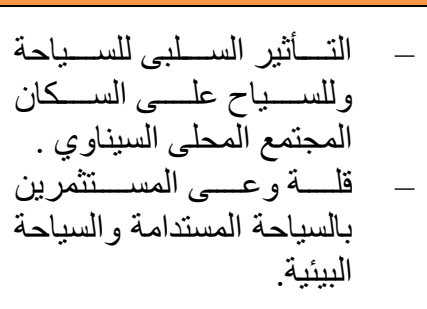 & 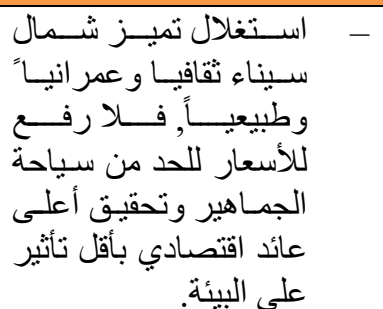 & 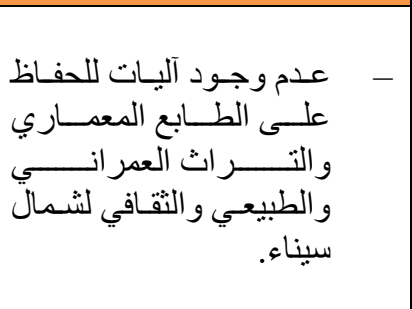 & 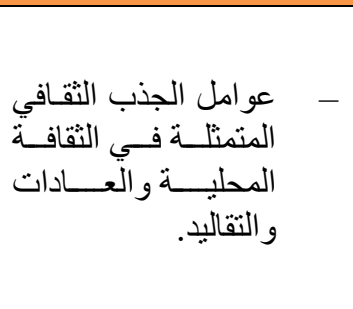 \\
\hline
\end{tabular}




\begin{tabular}{|c|c|c|c|}
\hline 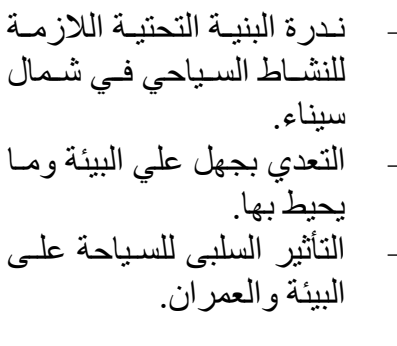 & 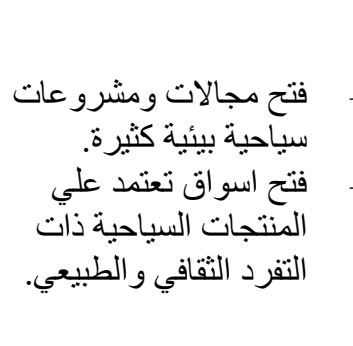 & 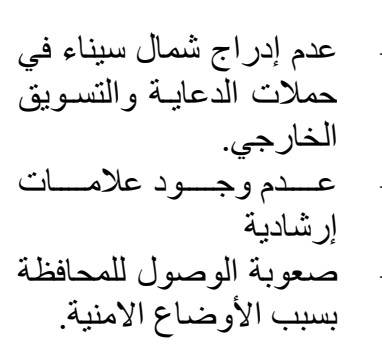 & 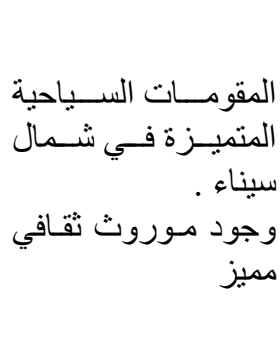 \\
\hline 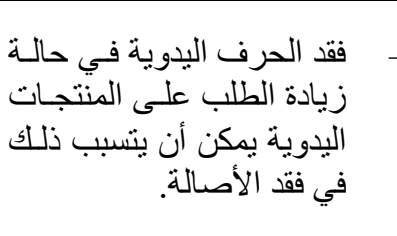 & 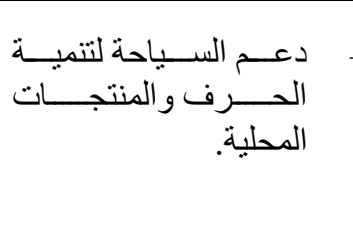 & 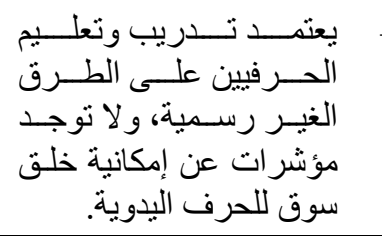 & 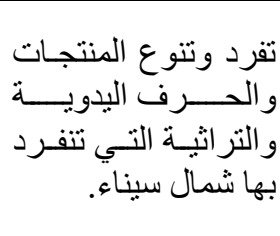 \\
\hline
\end{tabular}

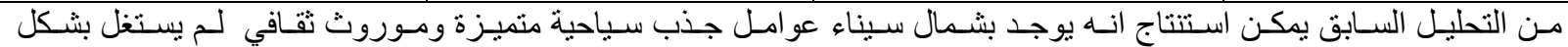

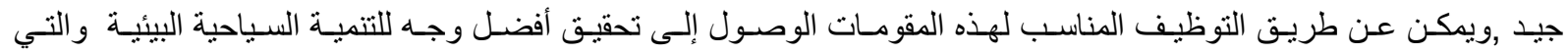

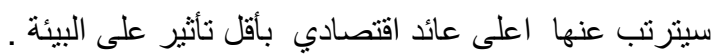

\section{7- دراسة حالة المنشآت السياحية البيئية بشمال سيناء وإمكانية تطبيق الاستدامة عليها}

أسباب اختيار عينات الدر اسة:

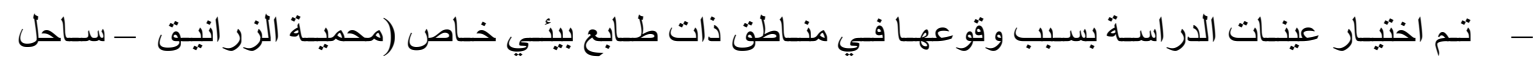

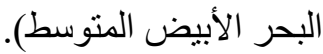

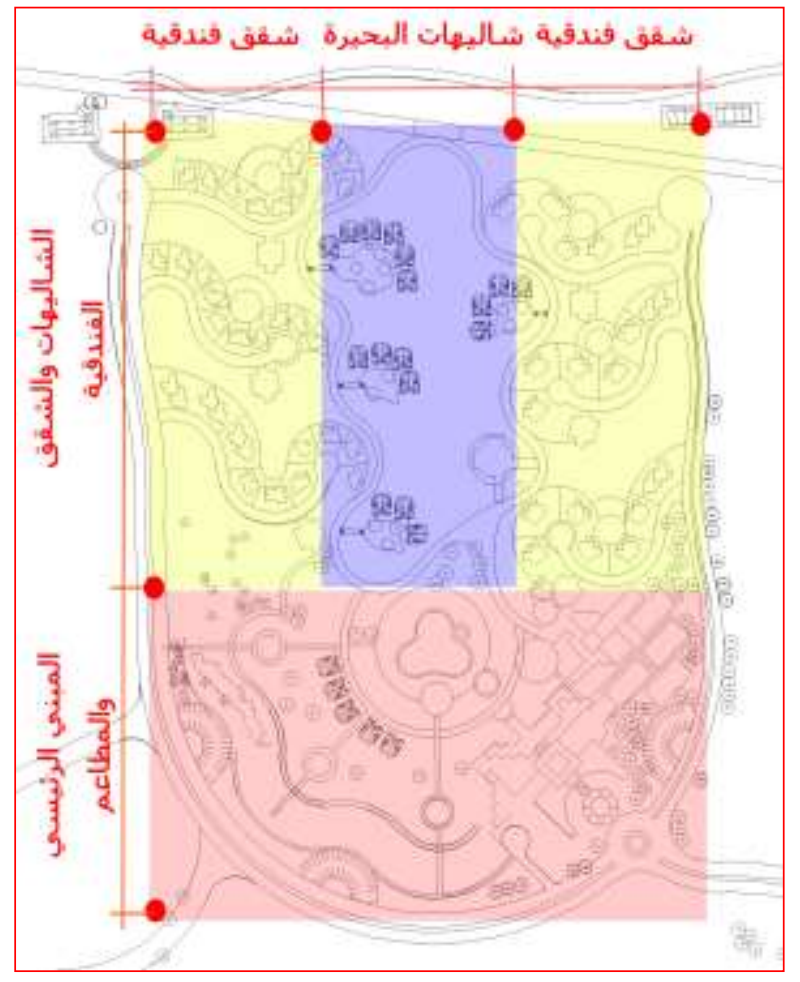

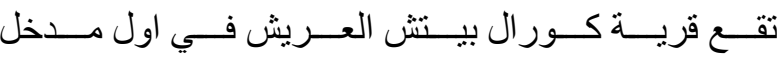

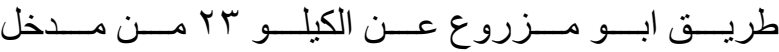

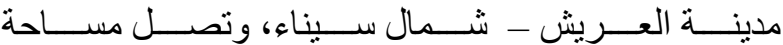

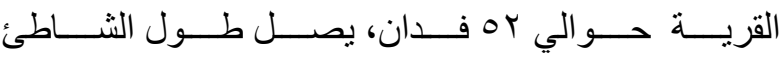

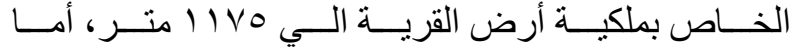

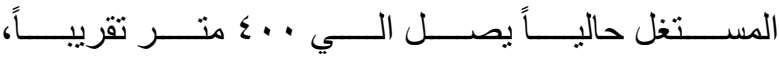

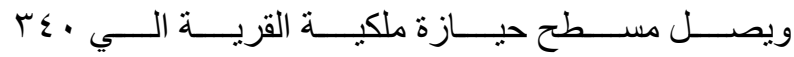

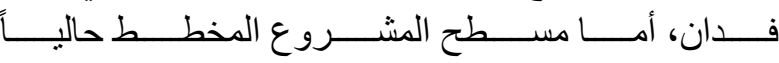

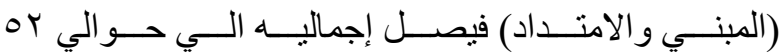
فدان، والقرية مصنفة ه نجوم سياحياً. اولاً:معايير التخطيط البيئي أـ احتر ام خطوط الكنتور بالموقع:

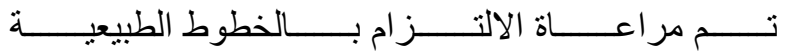

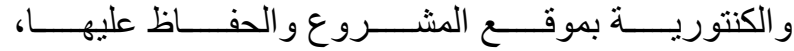

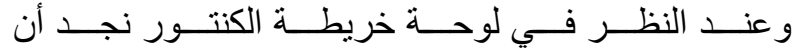

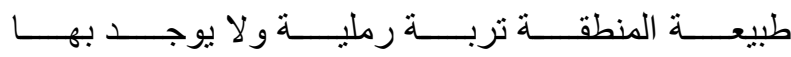

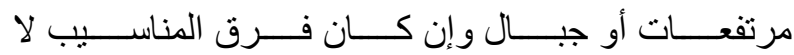

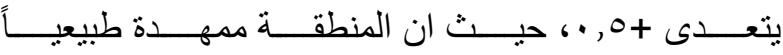

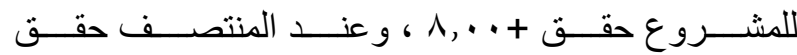

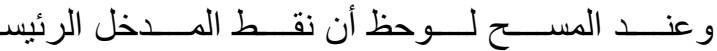

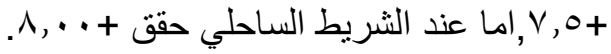

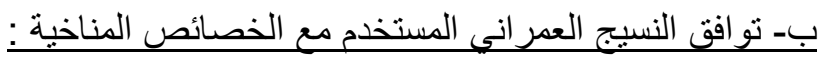




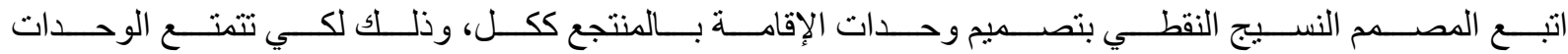

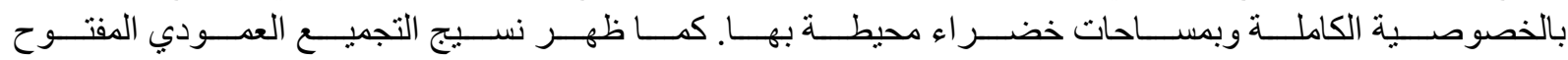

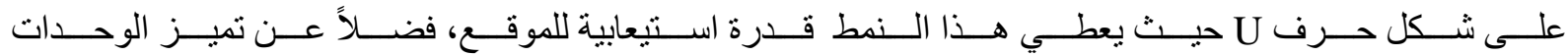
بالتوجيه الجيد وتحقيق أكبر قدر من التمتع بالرؤية المزدوجة للبحر و البحيرة الصناعية . ثانياً:معايير التصميم البيئي

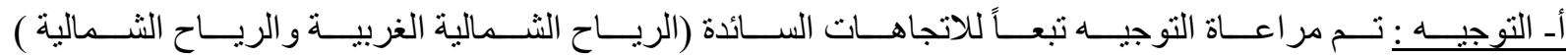

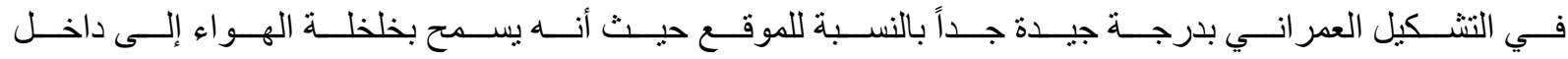

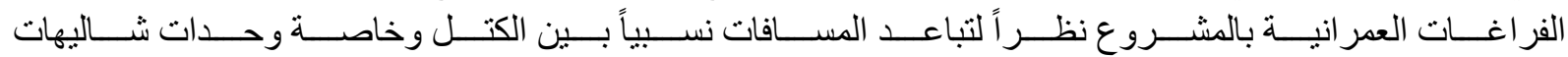

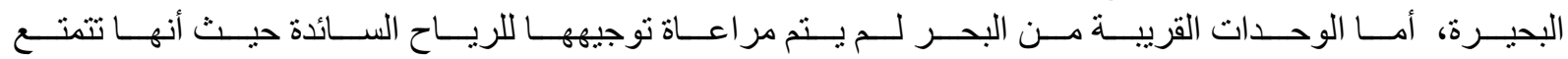

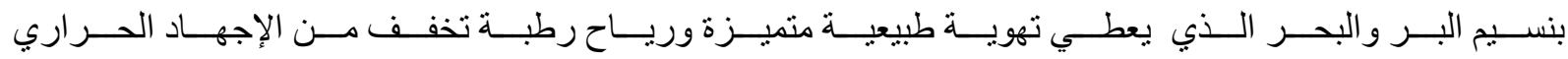
الناتج من أشعة الثمس.

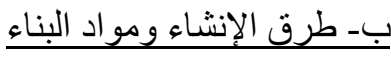

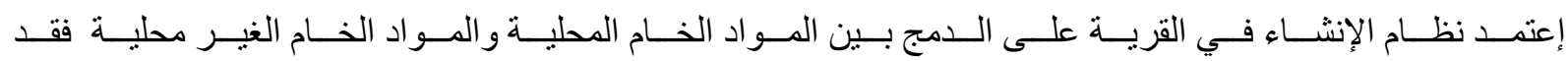

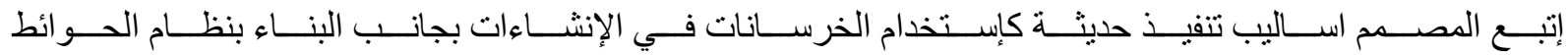

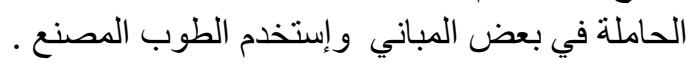
ج- تصميم الغلاف الخارجي

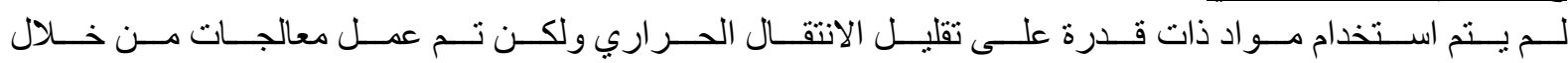

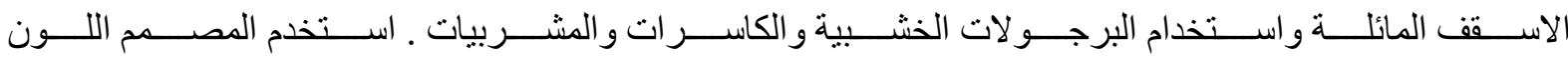

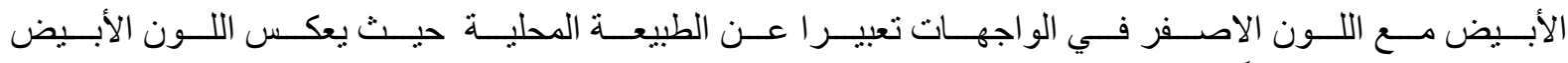

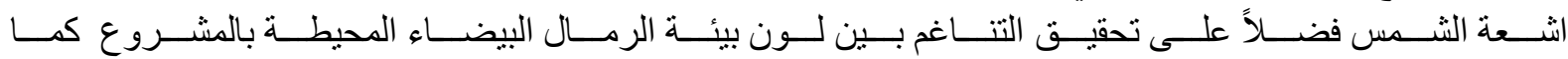

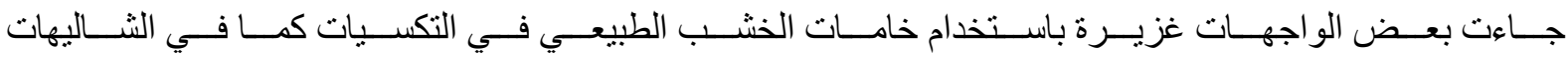

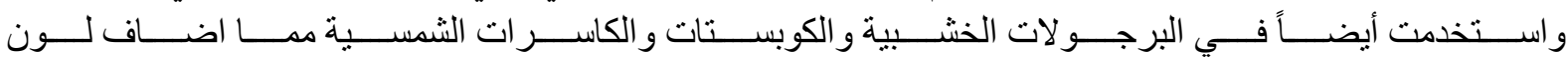

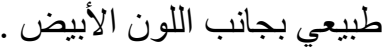

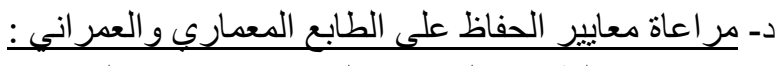

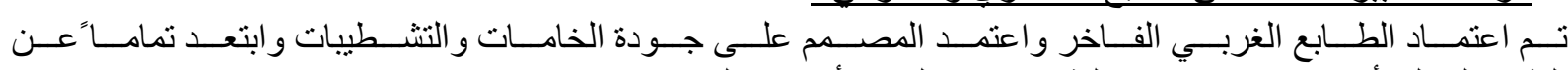
الطابع المحلي أو استخدام خامات محلية سو اء في الفرش أو مو اد البناء.
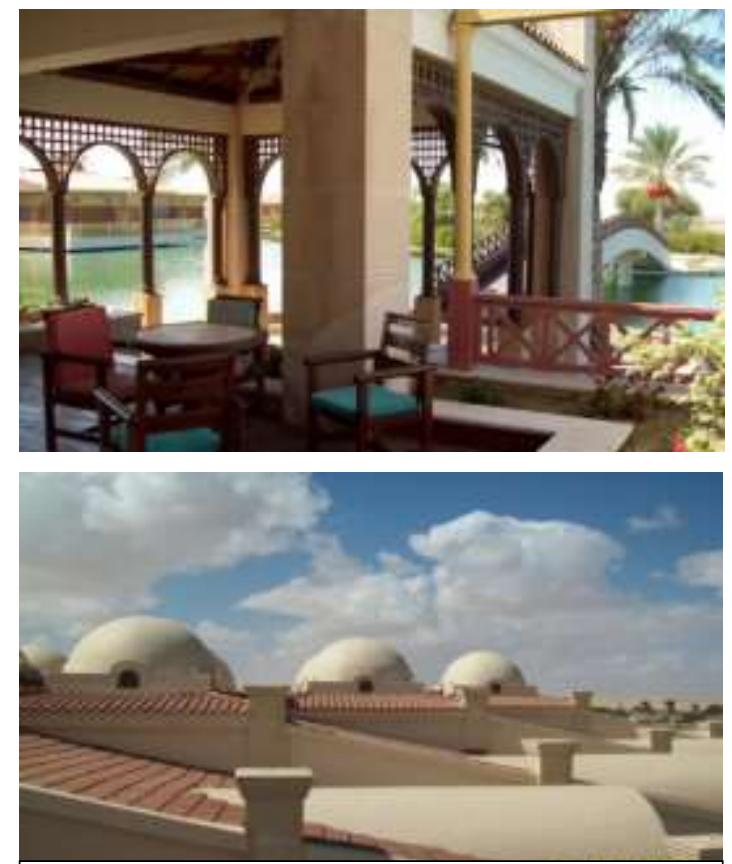

تم تصميم القباب و القبو ات في أسقف الثـاليهات لزيـادة

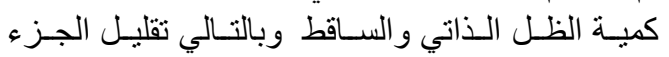

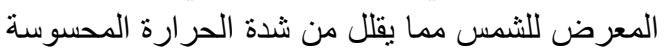

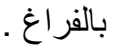

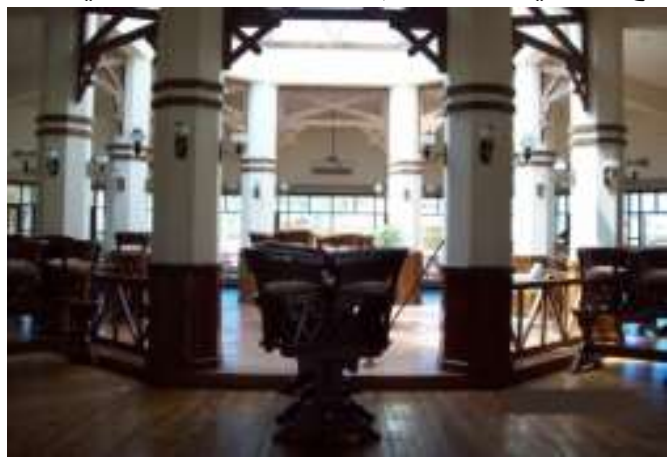

تــم اســتخدام الكاسـر ات الشمسـية و المشــربيات

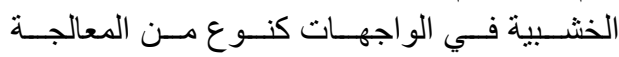

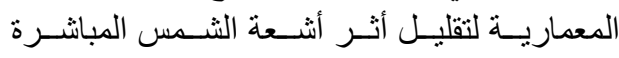

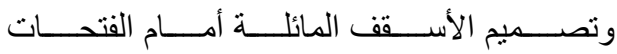

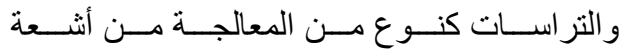
الثمس لتقوم بدور مماثل لكاسر ات الثمس.

شكل (r 1 ): تحليل الغلاف الخارجي والتكسيات لقرية كورال JAUES,16,59,2021 
ثالثاً: احترام الاشتراطات والقوانين البنائية والمعايير التخطيطية الموضوعة من قبل الدولة

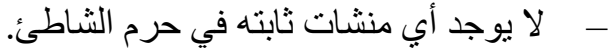

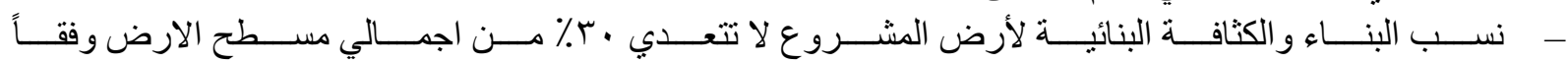
للمساحة الكاملة.

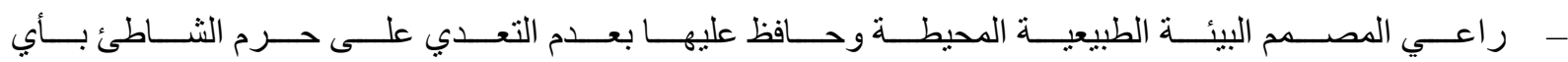
صورة مخالفة للقو انين و التشريعات البنائية.

رابعا:أسس الاستدامة لتنسيق الموقع العام

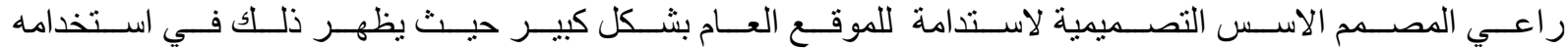

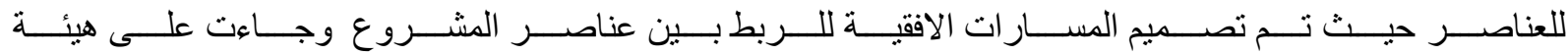

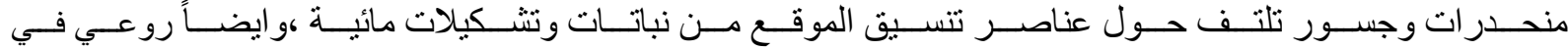

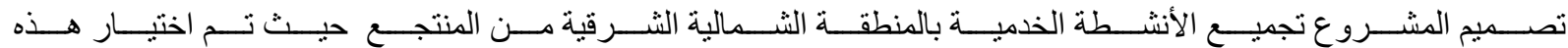

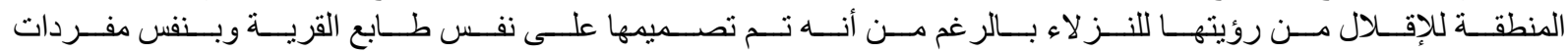

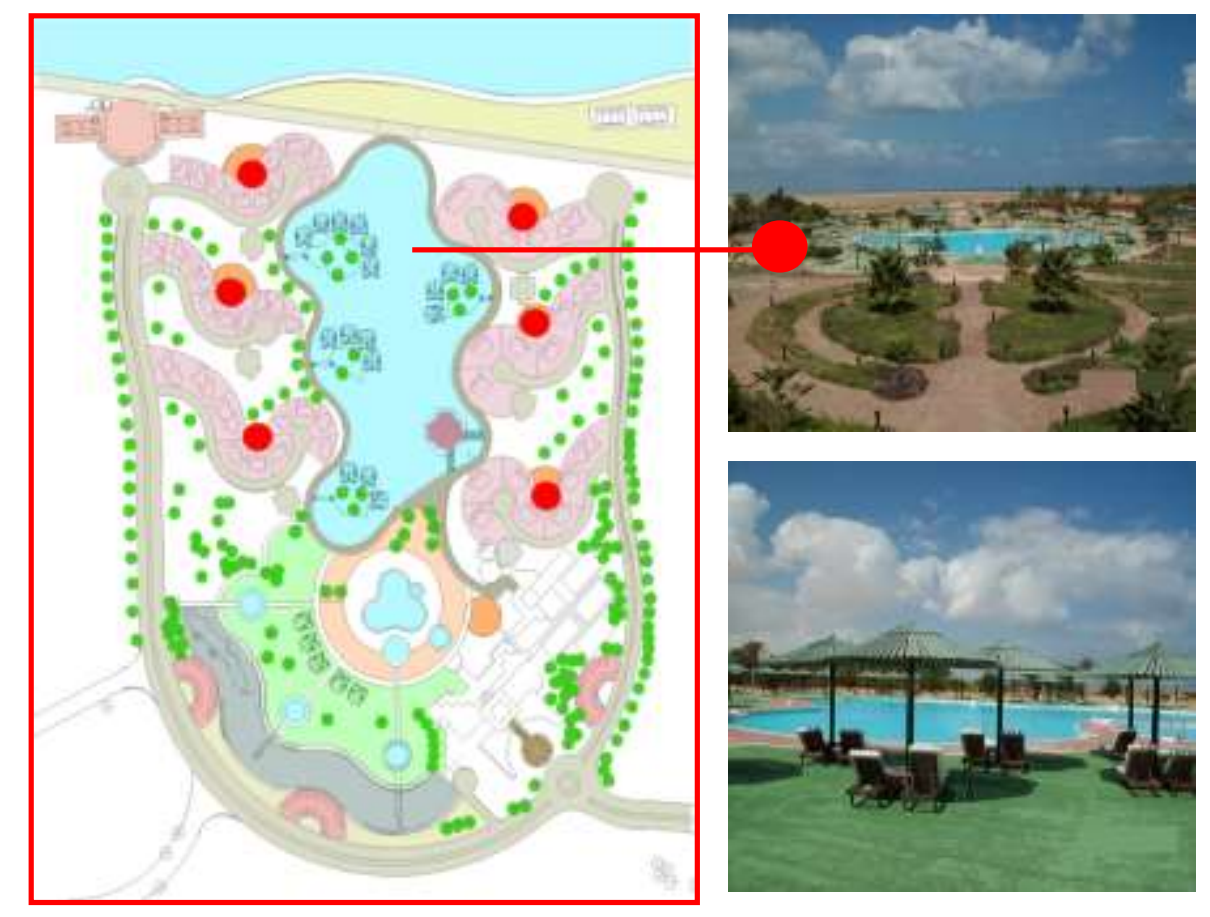

التصميم

\section{خامساً:الاستدامة لتصميم وتثثغيل شبكات البنية التحتية}

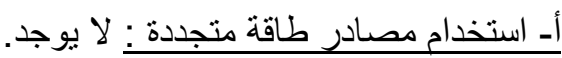

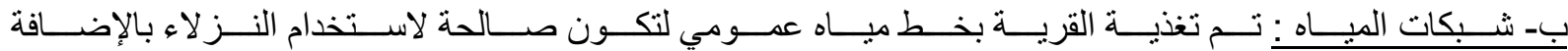

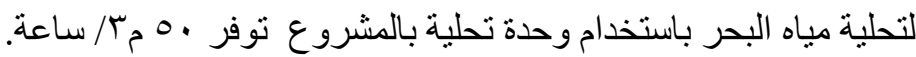

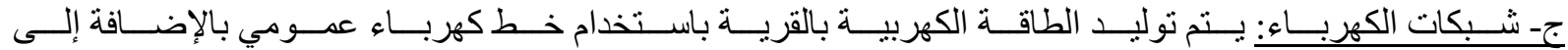

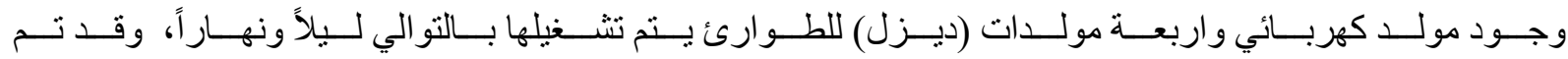

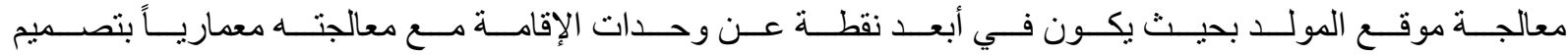
منشأ له نفس طابع المشروع لإخفاء المعدات داخله.

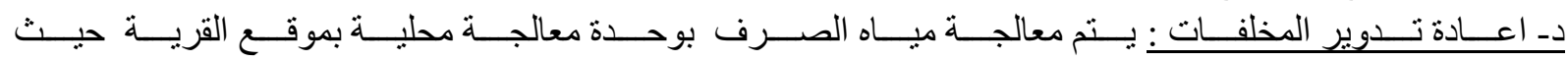

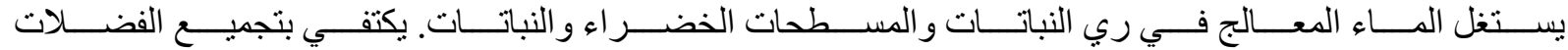




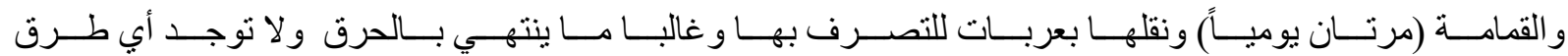
متبعة للفرز وإعادة التندوير.

سادساً:مشاركة المجتمع المحلي

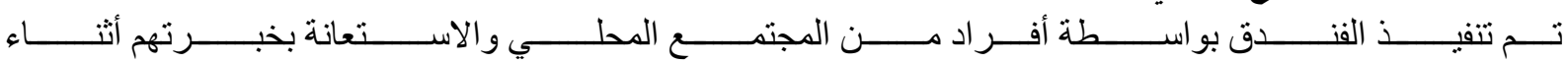

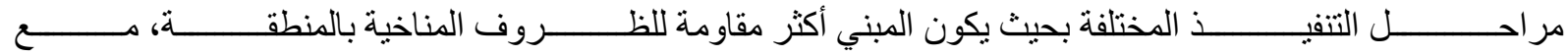

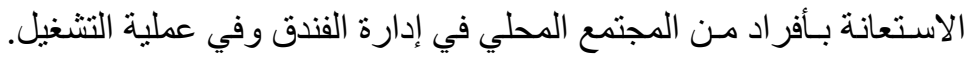
سابعاً :عمل دراسة الجدوى البيئية

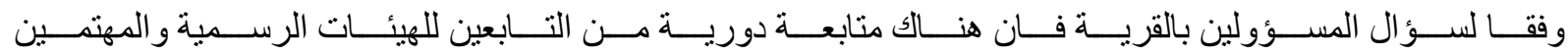

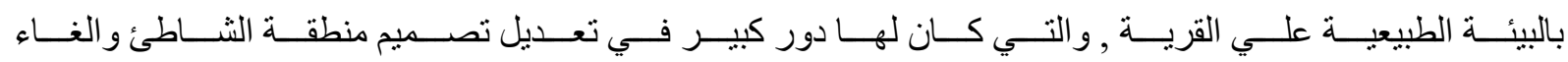

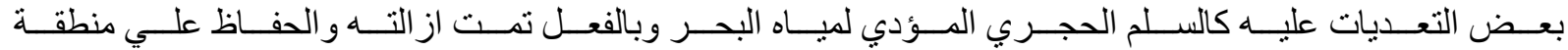

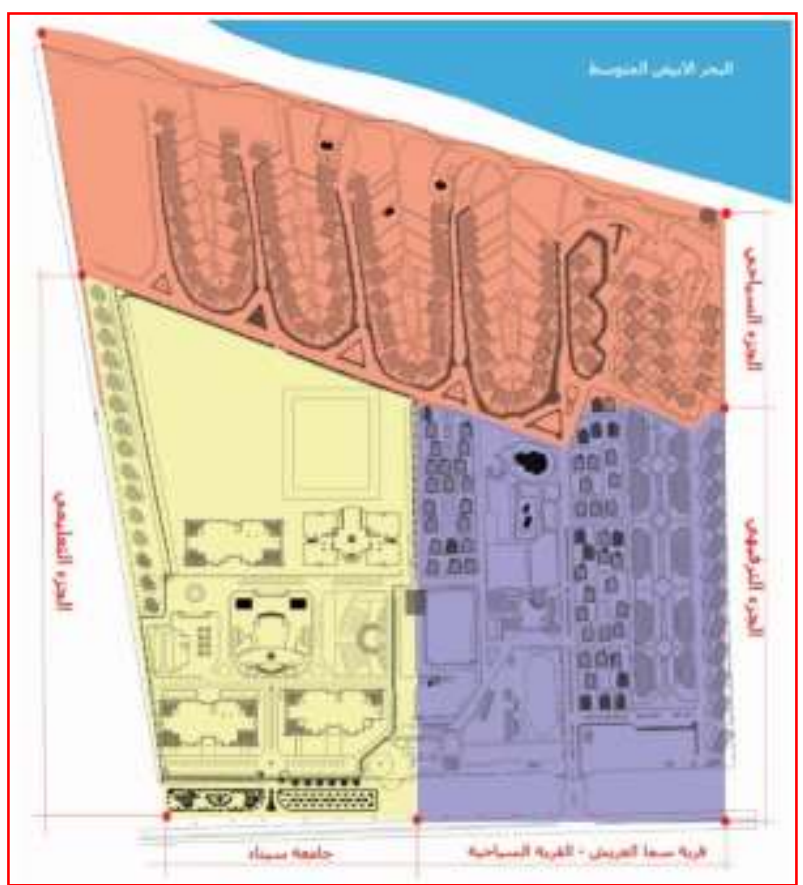

شكل ( ا 1): موقع قرية سما العريش بالنسبة لمحافظة شمال سيناء

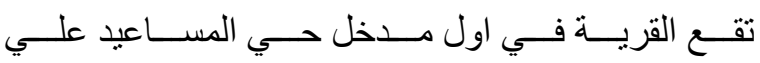

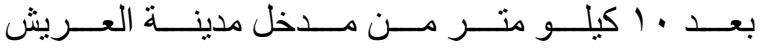

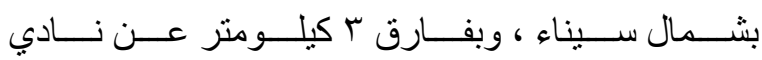

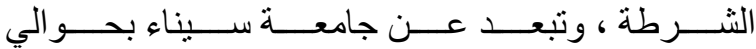

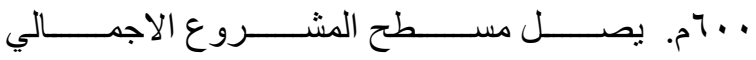

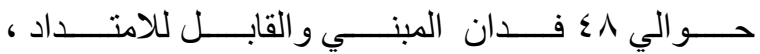

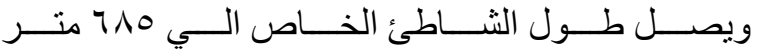
تقريياً، و القرية مصنفة ه نجوم سياحياً . اولاً:معايير التخطيط البيئي

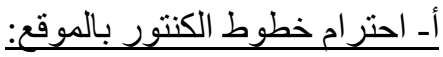

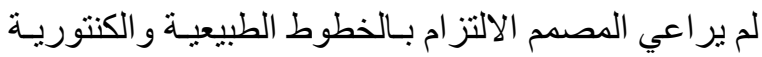

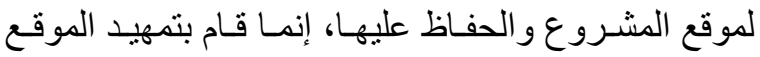

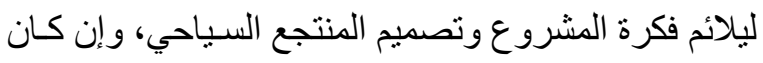

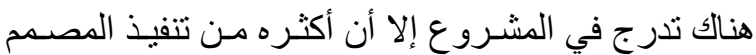

وليس كنتور اً طبيعياً.

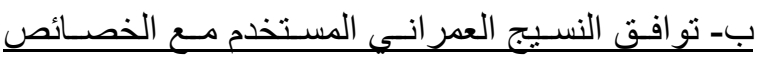
المناخية:

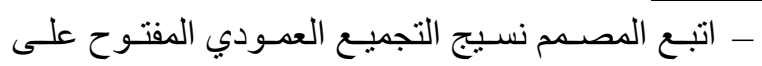

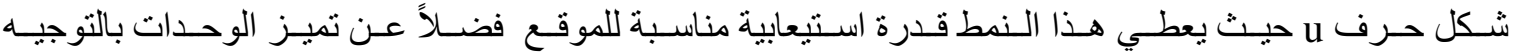

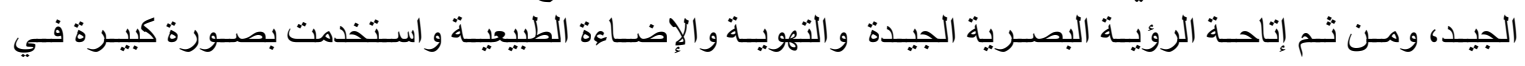

الفيلات U Villas.

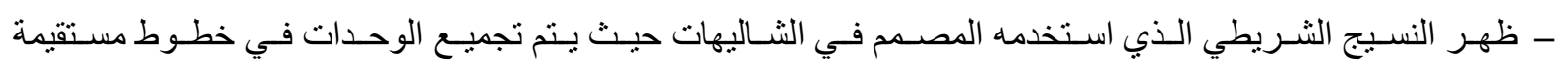
و عادة ما يكون لهذه الوحدات و اجهنان خار جيتين. ثانياً: معايير التصميم البيئي أ- التوجيه

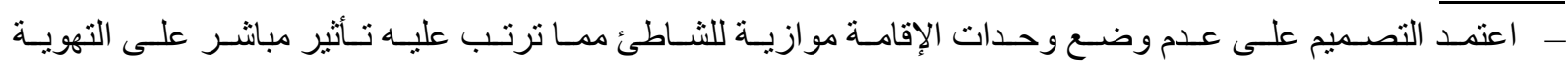

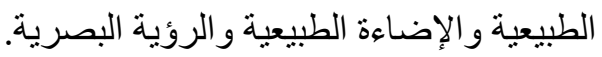

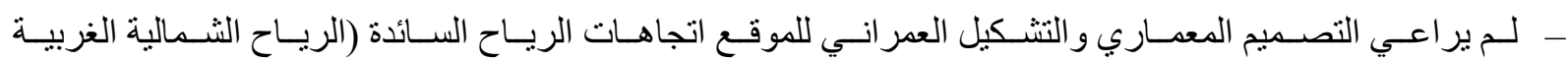

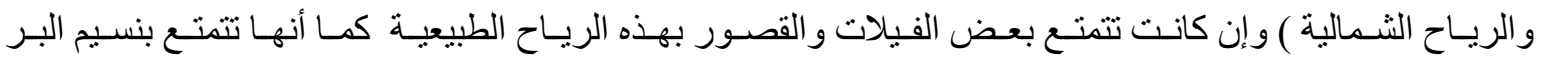
والبحر الذي يعطي تهوية طبيعية ومميزة ورياح رطبة تخفف من الإجهاد الحراري. بـ طرق الانشاء ومواد البناء 
- - اعتمد نظام الإنشاء في القرية على البناء بالخرسانات مع تداخل بسيط للمو اد المحلية كالأخشاب.

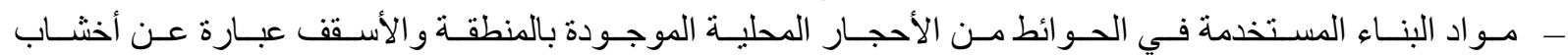

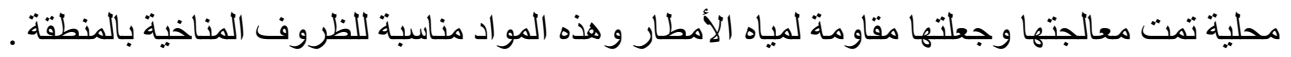

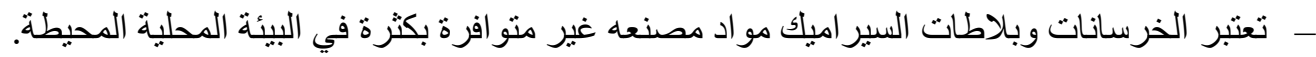

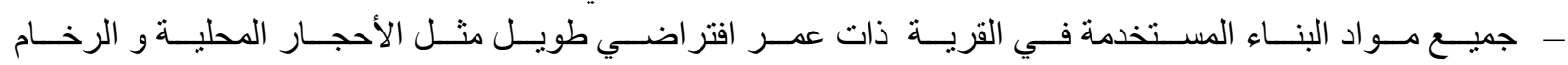

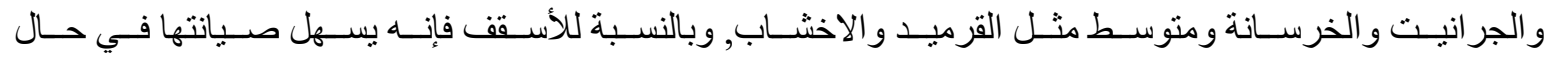
تعرضها للتلف.

ج- تصميم الغلاف الخارجي

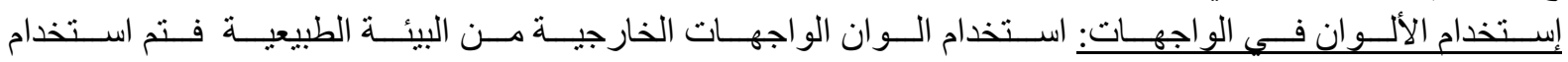

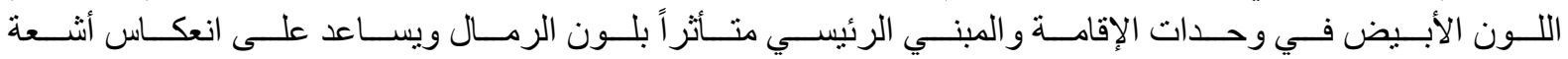
الثمس الأسقف من الخشب المحلي باللون البني.

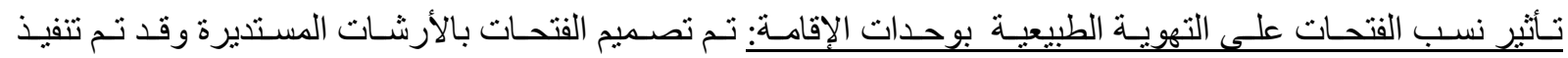

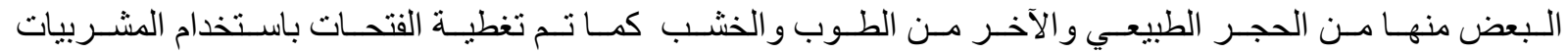

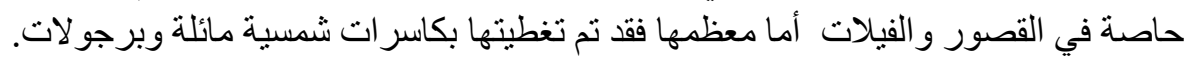

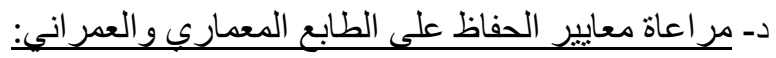

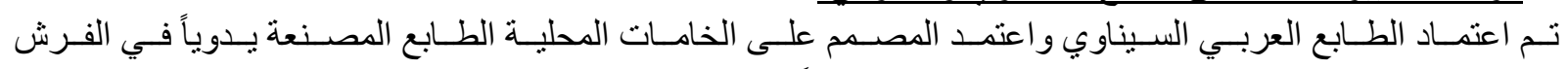

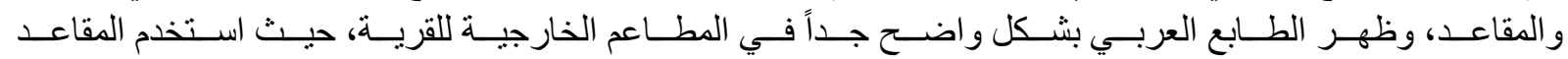

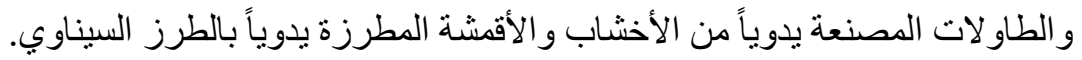
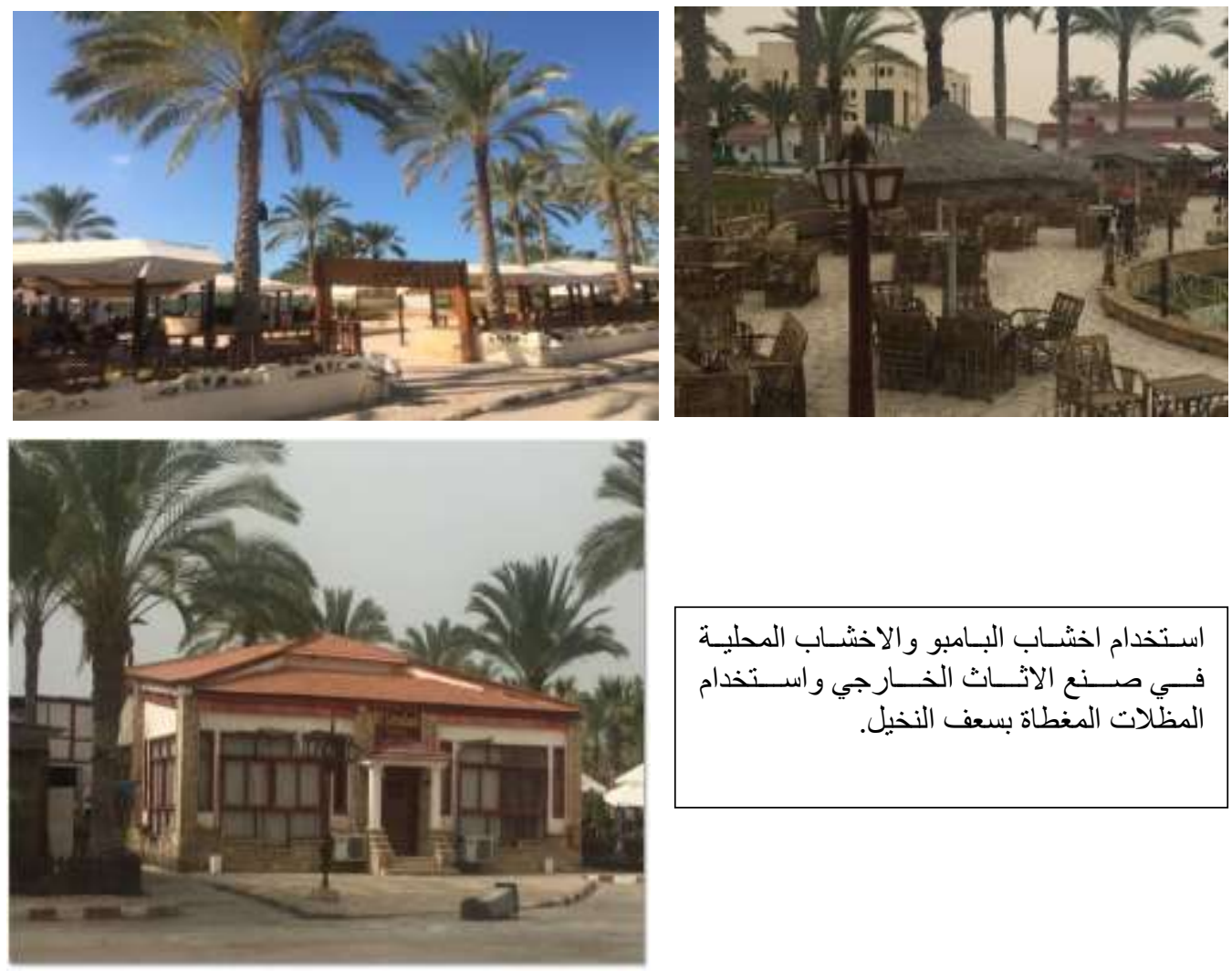

ثالثاً:احترام الاشتراطات والقوانين البنائية الموضوعة من قبل الدولة

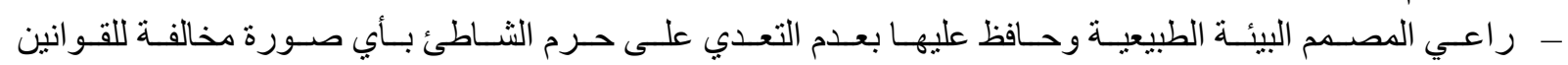
و التشريعات البنائية . - ل الا يوجد أي منشئات ثابته في حرم الثناطئ.

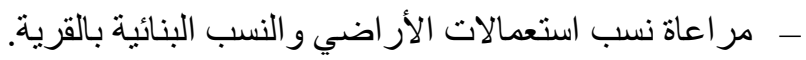




\section{رابعا:أسس الاستدامة لتنسيق الموقع العام}

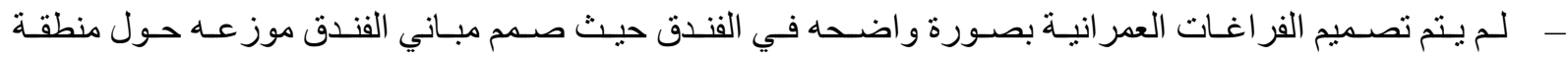

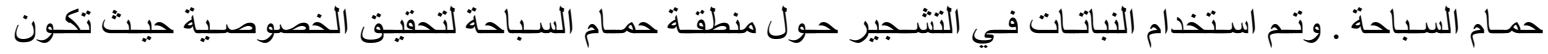
نفس النباتات الموجودة في البيئة المحيطة .

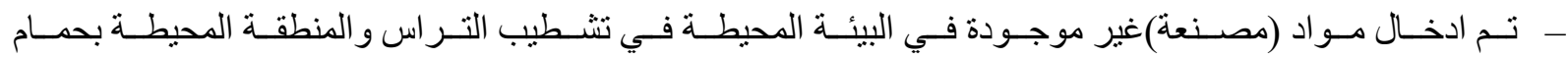
السباحة.

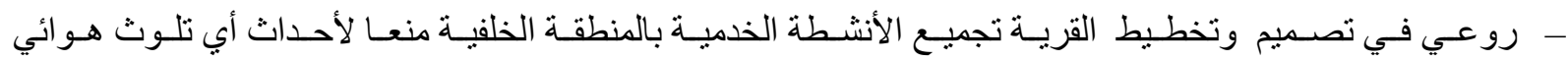

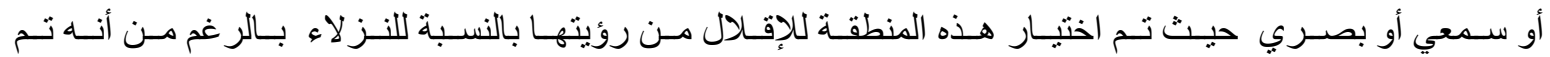

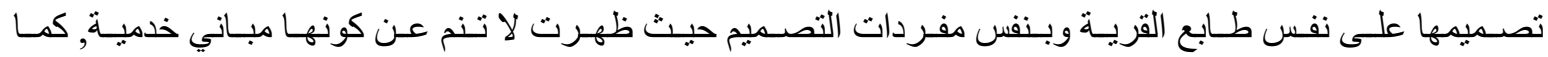

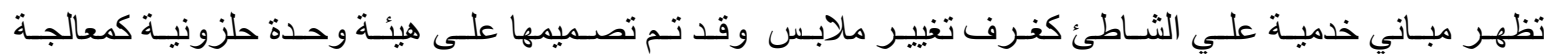
تصميمية لها وحتي لا تتنافر مع ملامح الثناطئ.

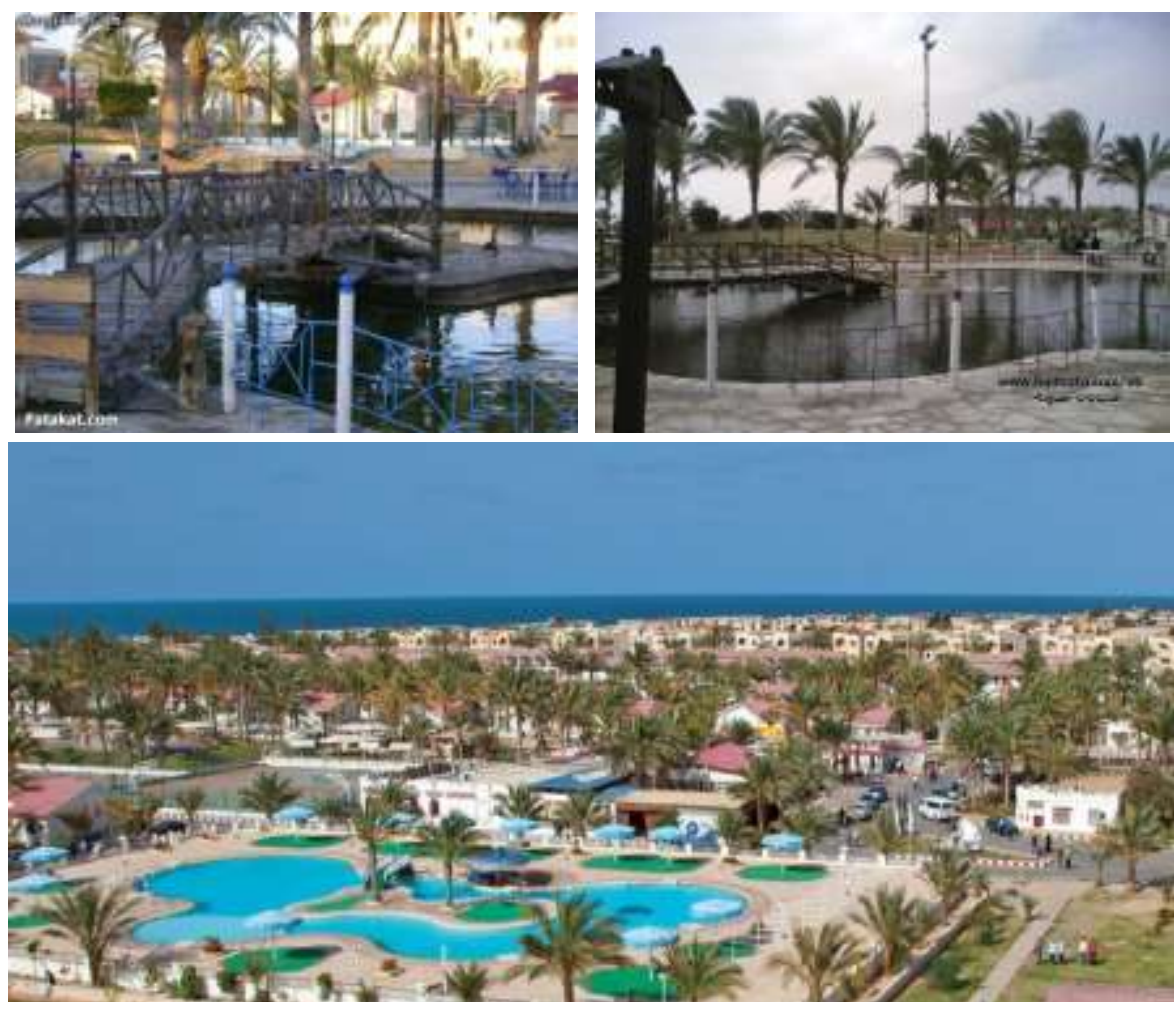

شكل (17 1): الموقع العام وتتسيق المواقع بقرية سما العريش

خامساً:الاستدامة لتصميم وتثغيل شبكات البنية التحتية

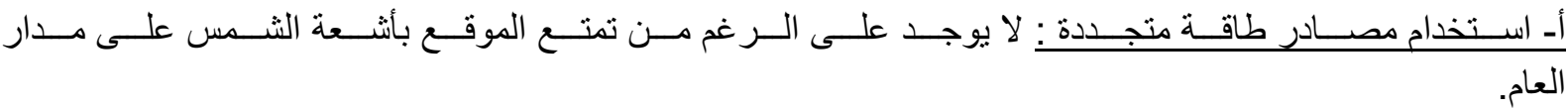

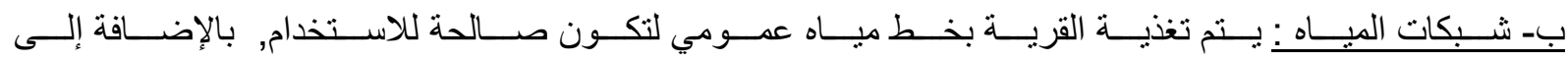

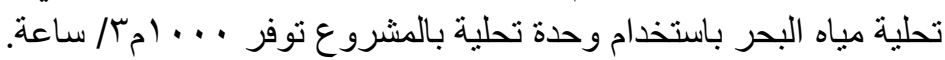

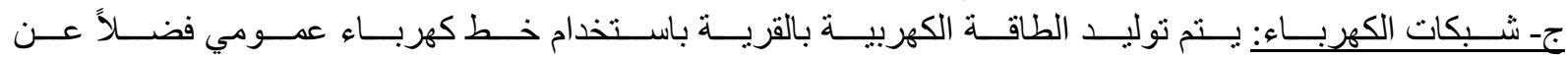

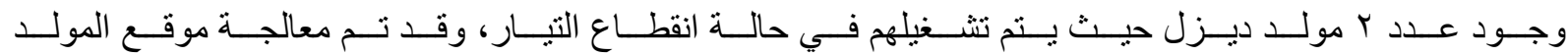

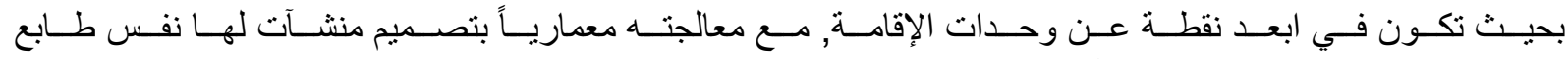

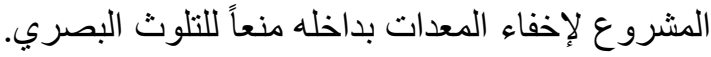

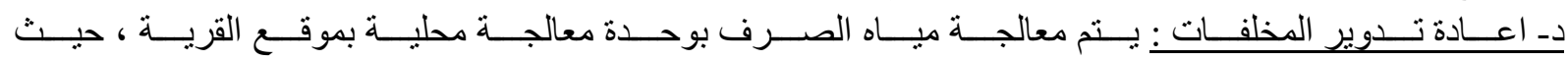

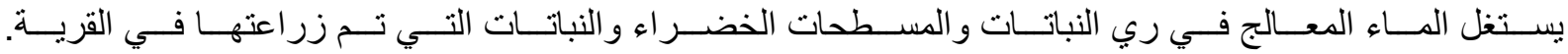




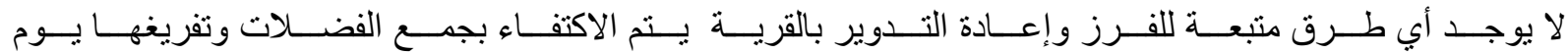
بعد الآخر ونقلها بعربات للتصرف بهرف بها و الذي غالباً ما ينتهي بالحرق.

سادساً:مشاركة المجتمع المحلي

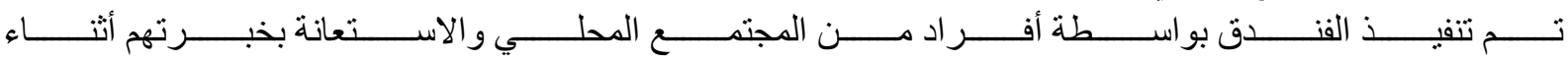

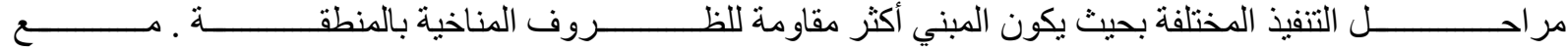

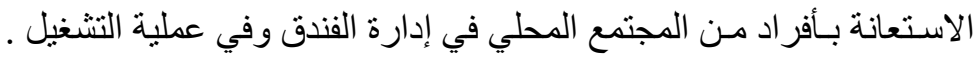

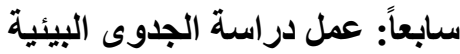

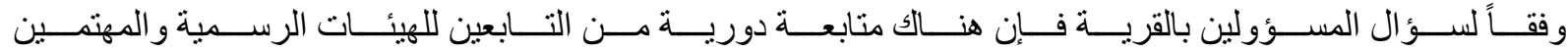

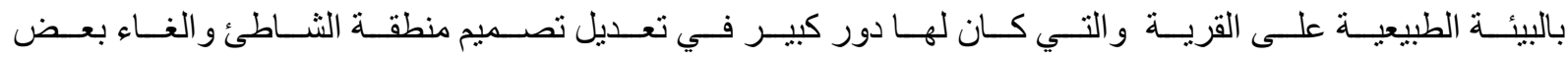

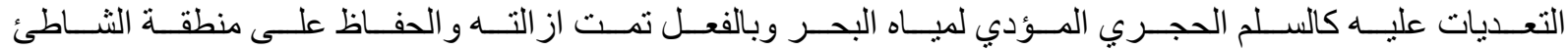
على طبيعتها .

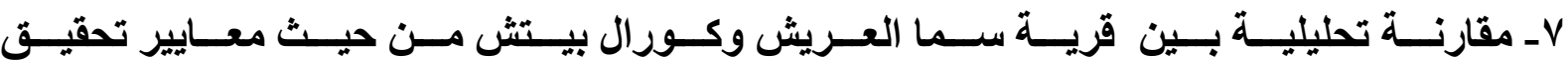
التنمية المستدامة : التهارة

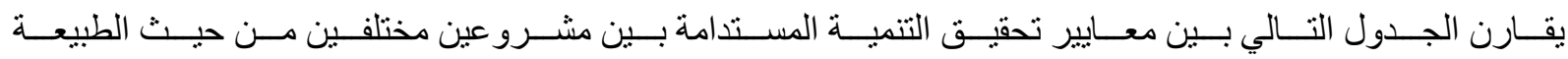

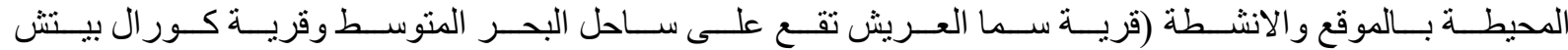

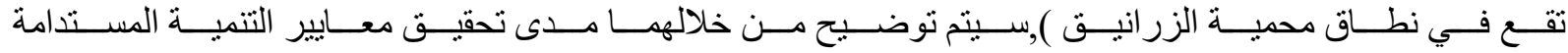

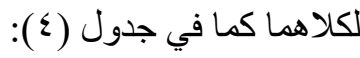

جدول ( ) ): تقييم الطبيعة المحيطة والمجتمع المحلي

\begin{tabular}{|c|c|c|c|c|}
\hline قرية كورال بيثش & قرية سما العريش & الخصائص & المقارنة & ت أ \\
\hline$\checkmark$ & $\checkmark$ & صحر اء رملية مع بعض التلال & \multirow{3}{*}{ وصف الموقع } & \multirow{12}{*}{ المبطيعة المبة } \\
\hline- & - & جبال على مرمي البصر & & \\
\hline - & $\checkmark$ & غابات من أشجار النخبل & & \\
\hline$\checkmark$ & $\checkmark$ & أشجار النخيل المزروعة & \multirow{3}{*}{ الموجودة النباتات } & \\
\hline$\checkmark$ & - & نباتات صحر اوية & & \\
\hline$\checkmark$ & - & زالمتناثر & & \\
\hline- & $\checkmark$ & العشش البدوية القريبة & \multirow{2}{*}{ المقافياة } & \\
\hline$\checkmark$ & - & مستقر ات المزار عين & & \\
\hline$\checkmark$ & $\checkmark$ & تحرية في وجود اصداف البحر و حيو انات & \multirow{4}{*}{ 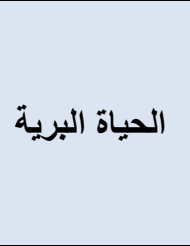 } & \\
\hline$\checkmark$ & - & الطيور الجارحة & & \\
\hline - & $\checkmark$ & طيور نورس & & \\
\hline$\checkmark$ & - & الجمال و الحيو انات البرية & & \\
\hline$\checkmark$ & $\checkmark$ & السباحة & \multirow{7}{*}{ الأنشطة } & \multirow{9}{*}{ والأشثطة } \\
\hline$\checkmark$ & - & رحلات السفاري في الصحاري المحيطة & & \\
\hline- & $\checkmark$ & التجمع العائلي الغير رسمي & & \\
\hline$\checkmark$ & $\checkmark$ & عزف الموسيقي بالطرق والآلات التقليدية & & \\
\hline- & - & snorkeling السباحة فوق الماء & & \\
\hline$\checkmark$ & $\checkmark$ & رحلات المر اكب البحرية & & \\
\hline$\checkmark$ & - & مر اقبة ومشاهدة الطيور & & \\
\hline- & - & ski jet ممنوع ركوب اللانشات البحرية و & \multirow{2}{*}{ الأنشطة } & \\
\hline- & - & ممنو ع الرياضات البحرية الملوثه للبيئة & & \\
\hline
\end{tabular}




\begin{tabular}{|c|c|c|c|}
\hline & & البحرية و المائية & \\
\hline- & - & ممنوع التلفيزيون و الفيديو & \\
\hline$\checkmark$ & $\checkmark$ & ممنوع الصيد & \\
\hline- & $\checkmark$ & بدو & \multirow{4}{*}{ الموعية } \\
\hline$\checkmark$ & $\checkmark$ & موظفين من المحافظات الأخرى & \\
\hline$\checkmark$ & $\checkmark$ & موظفين من العريش أو الثيخ زويد & \\
\hline$\checkmark$ & $\checkmark$ & 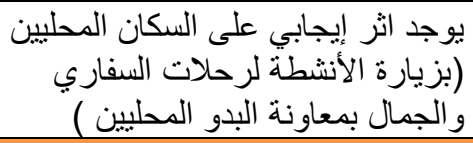 & \\
\hline$\bullet \bullet \bullet$ & $\bullet \bullet$ & (الإ) & \\
\hline
\end{tabular}

جدول (•): التقييم النهائي لمعايير تحقيق الاستدامة لمشاريع تقع ضمن إطار مناطق السياحة البيئية بشمال سيناء

\begin{tabular}{|c|c|c|}
\hline 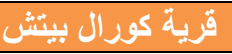 & قرية سما المبريش & 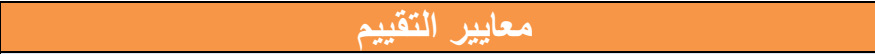 \\
\hline$\bullet \bullet \bullet$ & $\bullet \bullet$ & - - الطبيعة المحيطة بالموقع و الأنشطة و المجتمع. \\
\hline \multicolumn{3}{|r|}{ معايير تحقيق التتمية المستدامة } \\
\hline 000 & 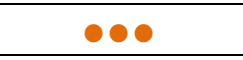 & - - معايير التخطيط البيئي. \\
\hline$\bullet \bullet$ & $\bullet \bullet \bullet$ & - - - معايير التصميم البيئي. \\
\hline$\bullet \bullet \bullet$ & $\bullet \bullet \bullet$ & - - احتـر ام الاشـتر اطات و القـو انين البنائيـة الموضـو عة مـن قبـل \\
\hline ○ & $\bullet \bullet \bullet$ & - - أسس الاستدامة لتنسيق الموقع العام. \\
\hline$\bullet$ & - & - الاستدامة لتصميم وتشغيل شبكات البنية التحتية. \\
\hline$\bullet \bullet \bullet$ & $\bullet \bullet \bullet$ & - - مشاركة المجتمع المحلي. \\
\hline ○ & $\circ$ & - عمل در اسة الجدوى البيئية . \\
\hline 00 & 000 & التقييم العام \\
\hline مقبول & & جيد جذاً \\
\hline$\bullet$ & & $\bullet \bullet \bullet$ \\
\hline
\end{tabular}

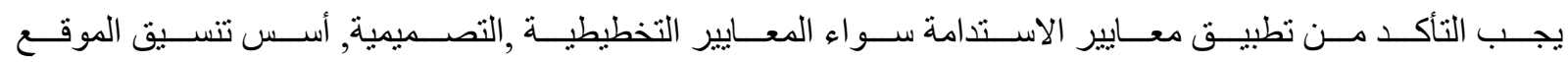

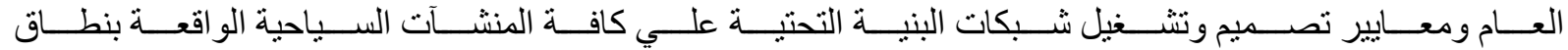

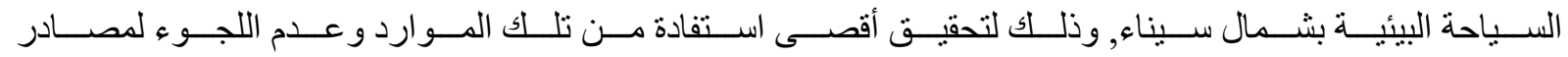

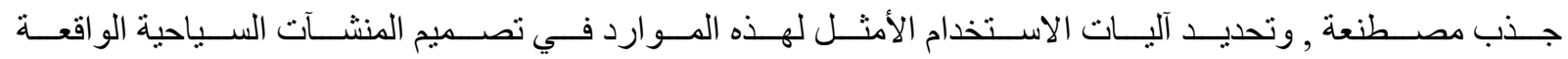
بإطار مناطق السياحة البيئية بما يتلائم مع بيئة شمال سيناء.

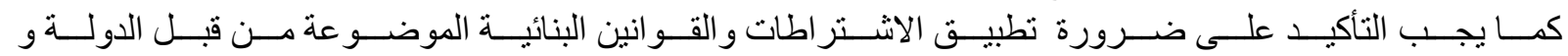

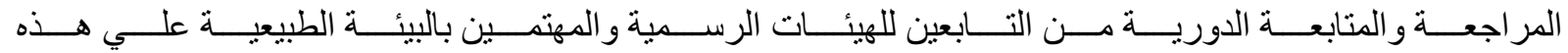
المشرو عات.

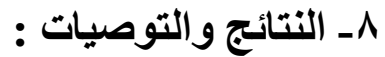

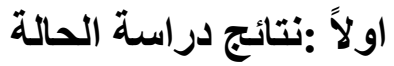

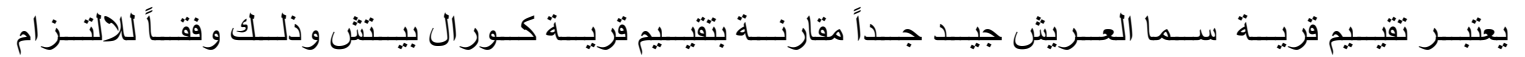

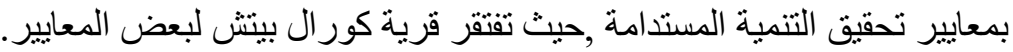

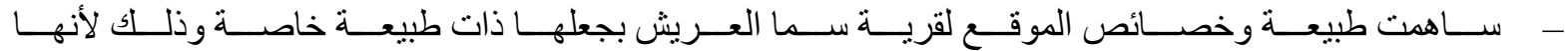
من أهم المحددات و المعايير التي لابد من مر اعاتها عند التصميم و التشكيل العمر اني. 


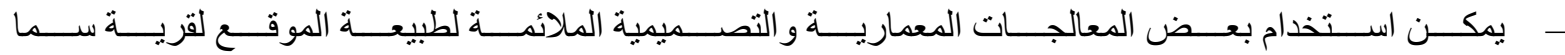

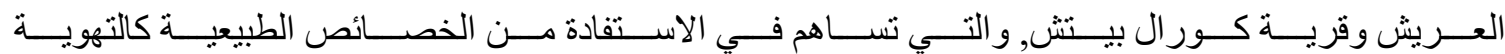

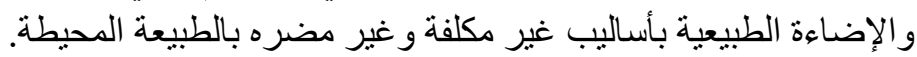

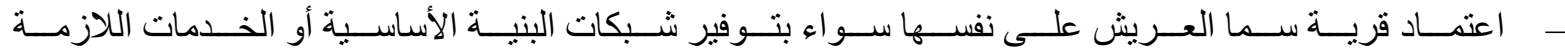
لتشغيل القرية يمثل مصدر قوة بدعم تحقيق مبادئ التتمية المستدامة للسياحة البيئية.

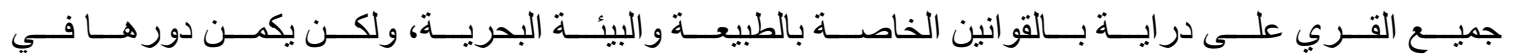

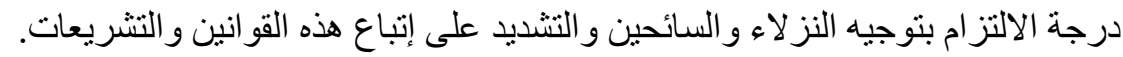

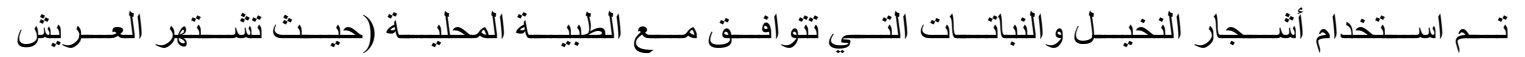

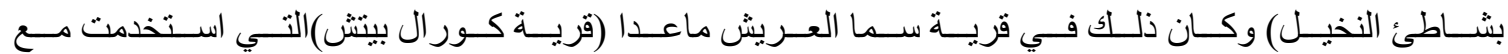

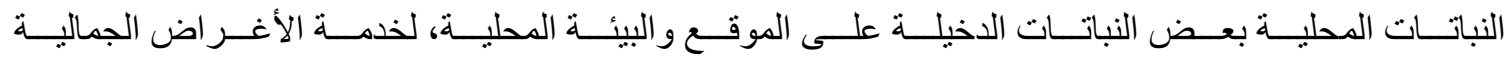
دون الاعتبار بتكاليف الري و الصيانة و المتابعة التي تحتاجها هذه النباتات. ثانياً :نتائج الاراسة:

- - شمال سيناء تتمتع بمقومات سياحية بيئية خاصة ومنفردة عن باقي المناطق السياحية البيئية.

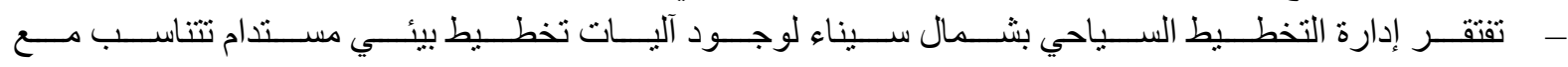

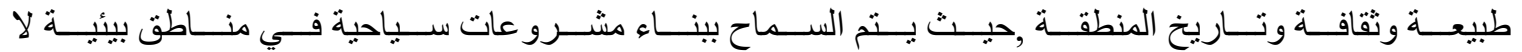

تنتاسب في خصائصها مع المنطقة. لا يوجد التزام عملي بنطبيق معايير التنمية السياحية البيئية المستدامة بشمال سيناء.

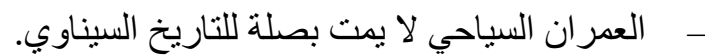

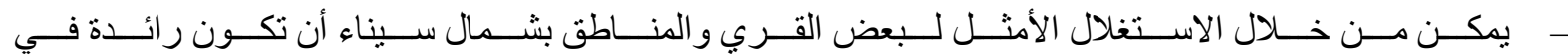
مجال التنمية السياحية البيئية المستدامة. - يمكن من خلال وجود فنادق غير بيئية استنز اف مقومات شمال سيناء البيئية و السياحية.

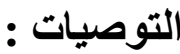

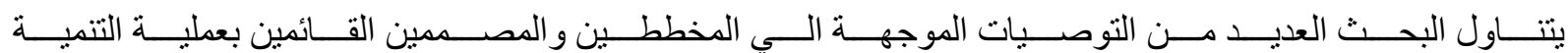
السياحية البيئية في اطار التوافق مع الطبيعة ويمكن تصنيف هذه التوصيات الي ما يلي: توصيات تخطيطية:

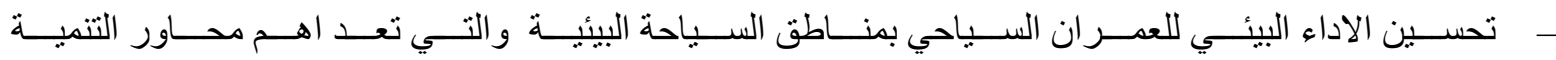
السياحية المستدامة بمصر.

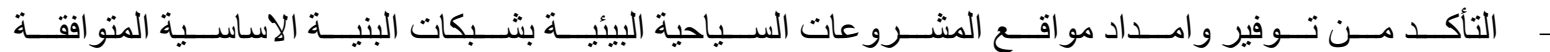
بيئيا مع طبيعة المنطقة لإقامة عملية التنمية السياحية المستدامة بيئياً. توصيات معمارية وتصميمية:

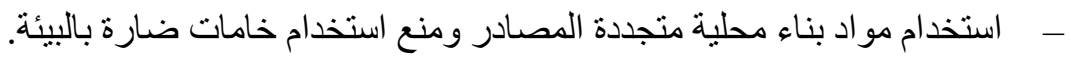

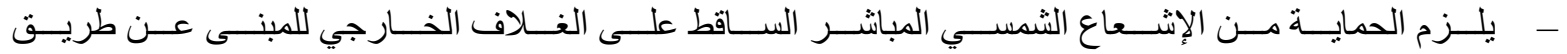
المعالجات المعمارية المختلفة. - - مياه المباني بما يضمن تحقيق رؤية متميزة.

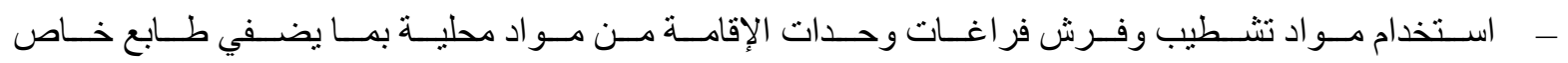
للمنشآت السياحية. - - استغلال العمالة المحلية و التي تتمتع بتر اث وخبرة محلية وتصميميه وتنفيذية كبيرة. توصيات خاصة بعناصر تنسيق الموقع العام:

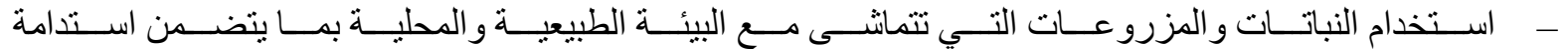
الحياة لهذه النباتات.

توصيات تقنية:

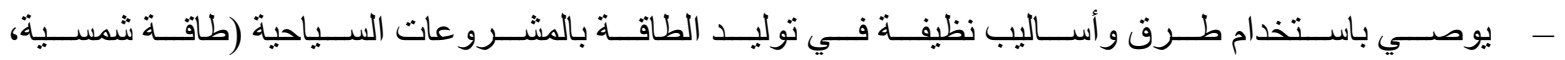
طاقة الرياح.. إلخ). 


\section{- - يوصى بإعادة استخدام ماء الصرف بعد المعالجة في أعمال الري وتسميد التربة.} - - يوصي بإتباع مبدأ إعادة الفرز واءو التدوير في إدارة المخلفات.

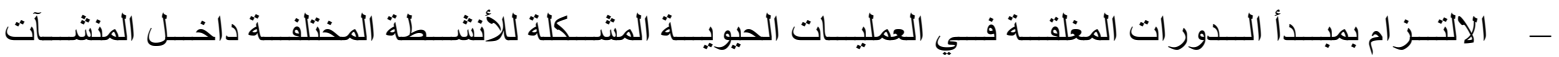
السياحية.

- - ـ ضرورة الاهتمام بإنشاء الفنادق البيئية و التي تحقق مفاهيم التنمية السياحية البيئية المستدامة.

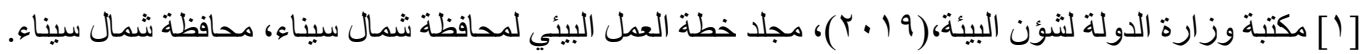

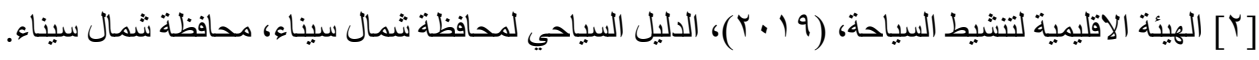

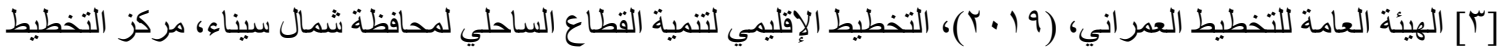
العمر اني لإقليم قناة السويس.

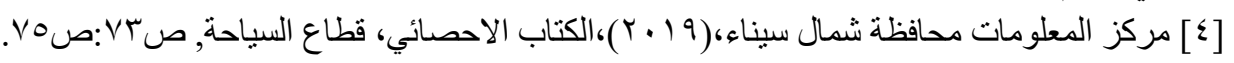

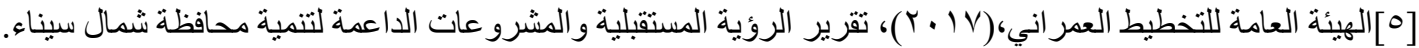

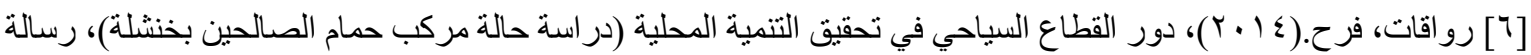

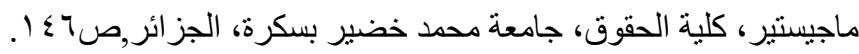

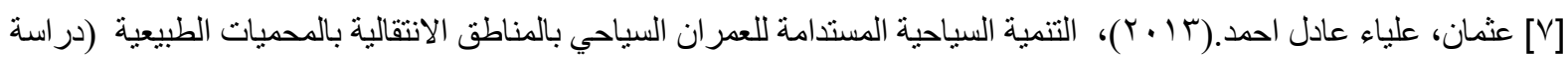

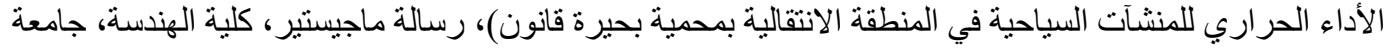

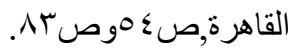

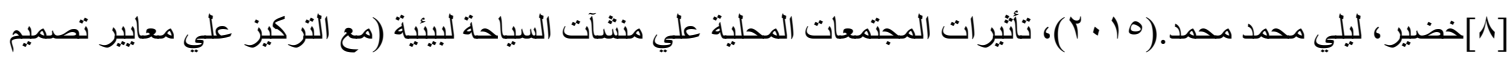

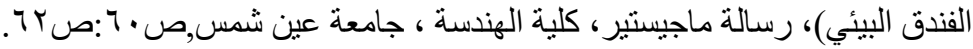

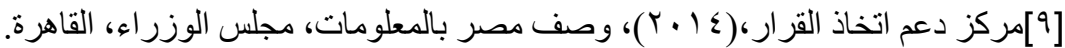

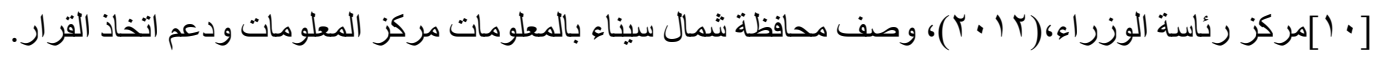

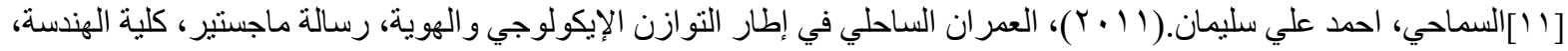

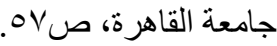

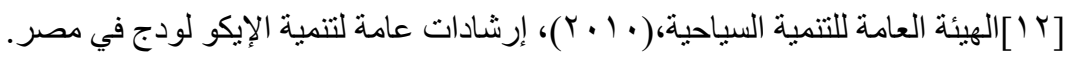

